\title{
On intermittent renewable generation \& the stability of Australia's National Electricity Market
}

\author{
Paul Simshauser* \\ Griffith Business School \\ Griffith University \\ April 2017
}

\begin{abstract}
Energy-only markets have an inherently unstable equilibrium, even under ideal conditions, because participants are unable to optimise VoLL events. The addition of intermittent renewable generation is thought to make conditions harder. In this article, optimal VoLL events in an islanded NEM region is modelled by substituting high price caps for Boiteux capacity charges, then analysing the impact of adding progressively more Variable Renewable Energy (VRE) - up to 35\% market share. Spot market conditions prove stable and tractable provided thermal plant exit and adjust perfectly. But VRE asset allocation is important; absent highly elastic demand or ultra-low cost storage solar PV market share has economic limits because the technology rapidly cannibalises itself. Furthermore, as VRE rises in imperfectly interconnected regions, a tipping point appears to exist where the hedge market enters an unstable zone through shortages of 'asset-backed' firm intra-regional swaps and caps. Government-initiated CfDs for VRE need to be designed carefully to ensure any instability is not exacerbated by extracting contracts from an already short hedge market.
\end{abstract}

Keywords: Energy markets, missing money, renewables.

JEL Codes: D61, L94, L11 and Q40.

\section{Introduction}

Australia's National Electricity Market (NEM) formed part of a world-wide electricity industry microeconomic reform experiment which commenced in Chile from 1982 (Pollitt, 2004). England \& Wales followed with their landmark 1990 reform while Australia commenced from 1994 (Green, 1998; Nelson \& Orton, 2016). The initial wave of restructuring and deregulation had two or three template electricity markets designs involving various combinations of 'energyonly' or 'capacity \& energy' market mechanisms, set in gross or net pools with day-ahead or realtime scheduling. These designs shared a market liberalisation objective but adopted different paths to achieve that outcome (Pollitt \& Anaya, 2016). Results have been mixed.

By any measure the NEM had been a resounding success ${ }^{1}$ and by 2005 was widely regarded as a template for power system reform (IEA, 2005). The NEM is an energy-only, gross pool with a real-time (5-minute) uniform first-price auction clearing mechanism and forward derivative markets traded both on-exchange and Over-the-Counter at $300-400 \%$ of physical trade. ${ }^{2}$

Pollitt \& Anaya (2016) noted a second wave of world-wide electricity market experiments currently underway - each involving a 'game-changing set of policies' designed to achieve a decarbonisation objective. Once again, there are two or three template designs involving various combinations of carbon pricing, renewable targets, centrally-initiated CfDs, and distributed resources. Pollitt \& Anaya (2016) note, as with the first wave results will be mixed.

* Professor of Economics, Griffith Business School, Griffith University, Australia.

${ }^{1}$ Performance improvements were documented in average cost, price, plant availability, and reserve margins (see Simshauser, 2005).

In more recent research, the wholesale market was one of the few areas of the electricity market that was performing well (see for

example Nelson \& Orton, 2015; Simshauser, 2014). From mid-2016 however, market performance deteriorated significantly.

${ }^{2}$ See Simshauser, Tian \& Whish-Wilson (2015) and in particular Appendix III. 
When energy markets were first designed, they were applied to large thermal systems comprising dispatchable coal, gas and hydro plant. There was little intermittent generation plant (i.e. solar and wind). ${ }^{3}$ But Variable Renewable Energy (VRE) sources now form the dominant supply-side entrants in the NEM driven by various policy initiatives, an extremely tight market for gas $^{4}$, and an abject inability to 'bank' coal plant due future $\mathrm{CO}_{2}$ emissions risk.

Energy markets can comfortably integrate moderate levels of intermittent generation (Hirth, 2013)..$^{5}$ However, there is a broader question as to whether current energy markets are capable of accommodating high-levels of VRE. To see why, consider the following based on Pollitt \& Anaya (2016). Later in this article, the Queensland power system is modelled with $35 \%$ VRE. A preview of the challenge is as follows. In 2016 Queensland maximum demand was 9500MW and energy demand was $57,000 \mathrm{GWh} .{ }^{6}$ In order to meet reliability constraints, the supply-side requires a $13 \%$ reserve plant margin or $10750 \mathrm{MW}$ of generating capacity (i.e. $9500 \mathrm{MW}$ x 1.13 ). Average demand is 6600MW and generation fleet utilisation is 61\% (i.e. 6600/10750).

Now consider the same system with 35\% VRE. The capacity factor of rooftop Solar PV is 17\% and utility-scale wind and solar sites in QLD are $40 \%$ and $28 \%$ respectively. To meet $35 \%$ or $19,000 \mathrm{GWh}$ renewable market share $6500 \mathrm{MW}$ of VRE capacity needs to be added including 1500MW of small-scale solar PV and 5000MW of utility-scale wind and solar plant. Coincident peak output from the VRE fleet is $4500 \mathrm{MW}$ and minimum output is $500 \mathrm{MW}$. $^{7}$

We therefore have a situation where $38 \%(6500 /[10750+6500])$ of plant capacity is VRE, but VRE output could be as much as $68 \%(4500 / 6600)$ or as little as $8 \%(500 / 6600)$ of system demand. ${ }^{8}$ In this example, thermal plant utilisation falls from $61 \%$ to $47 \%$ and will test technical limits under security-constrained dispatch. The question that logically follows is; can energyonly markets can cope with high levels of VRE? Pollitt \& Anaya (2016, p74) suggest:

The simple answer to this question would seem to be: no. No, in the sense that very few current market arrangements are set up to support high shares of renewable electricity at politically acceptable prices and levels of security of supply. However, that does not mean that markets cannot adapt to the addition of more renewables...

While by no means unanimous, an emerging theme amongst British and European energy economists is that energy-only markets are broken given multiple policy objectives (Edenhofer et al. 2013; Helm, 2014; Newbery, 2015; Keay, 2016; Pollitt \& Anaya, 2016; Neuhoff et al. 2016; Green \& Staffell, 2016). The collapse of the South Australian power system (40\% VRE) on 28 September $2016^{9}$ - the first system collapse in Australia since $1964^{10}$ - removed any doubt in the minds of Australian policymakers that the NEM design requires adjustment. Whether this

\footnotetext{
${ }^{3}$ Data from the Energy Supply Association reveals that when the NEM commenced in 1998, the market shares of the various technologies were coal (88.4\%), hydro (9.3\%), gas (2.2\%) and VRE (0\%). Wind produced less than 1GWh in a 165,000GWh system. By 2015, the energy mix was coal (75.7\%), gas (12.9\%), hydro (6.4\%) and wind/solar (4.9\%) with total load of 196,000GWh. ${ }^{4}$ For further details on the Australian east-coast gas market, see Simshauser \& Nelson (2015).

${ }^{5}$ See for example Simshauser (2011) in which South Australia is modelled with 17\% VRE.

${ }^{6}$ Queensland's 2016 underlying System Maximum Demand was 9077MW and energy demand was 54,900GWh. Half-hour interval data is available at www.aemo.com.au. However, QLD also has 1500MW of rooftop Solar PV installed which is treated as a negative demand at the transmission system level. Adjusting for this means that headline Maximum Demand was about 9570MW and energy demand was about $57500 \mathrm{GWh}$.

${ }^{7} 4500 \mathrm{MW}$ is the $99^{\text {th }}$ percentile and $500 \mathrm{MW}$ is the $1^{\text {st }}$ percentile. The assumption underpinning this result is $5 \%$ market share for rooftop PV, 9\% market share for utility-scale solar PV and 21\% market share for wind.

${ }^{8}$ This is based on average demand. An examination of half-hour data revealed that output was as little as $7 \%$ and as much as $60 \%\left(1^{\text {st }}\right.$ and $99^{\text {th }}$ percentiles respectively).

${ }^{9}$ The characteristics that preceded SAs power system collapse are somewhat unique by global standards. SA has among the 'peakiest' system loads in the OECD, the highest take-up rate of rooftop solar PV per capita in the world, a very high market share of utilityscale VRE (primarily wind) which when combined with rooftop solar now produces $>40 \%$ of system demand. And, SA is interconnected to one adjacent region (i.e. Victoria).

${ }^{10}$ The New South Wales power system collapsed on 10 June 1964 during an electrical storm.
} 
translates to tweaking at the edges or major surgery is an open question but the status quo is widely acknowledged as unacceptable. ${ }^{11}$

In this article a region of the NEM is modelled with three objectives - to analyse whether with rising levels of VRE (1) stable spot market equilibrium exists for thermal plant; (2) how the market will view VRE asset allocation; and (3) imbalances that may emerge in forward derivatives markets thus presenting policymakers with systemic risks ${ }^{12}$. This article is structured as follows. Section 2 reviews relevant literature. Section 3 presents Model results of spot market stability and Section 4 explores VRE asset allocation. Section 5 analyses the hedge market. Conclusions follow.

\section{Review of literature}

Energy policy starts with three basic objectives; (1) a reliable supply (2) at minimum cost, (3) subject to an environmental constraint. For elected officials, reliability is crucial. Reliability is an all-encompassing term but can be broken down into Resource Adequacy and System Security (Batlle \& Perez-Arriaga, 2008). Resource Adequacy refers to sufficient installed capacity to meet instantaneous aggregate final demand, taking into account planned and forced plant outages. Security refers to the ability of Resources to withstand sudden disturbances arising from the loss of system elements in real-time. In energy-only markets, Resource Adequacy and Security are thus public goods (Newbery, 2015).

At the core of the current analysis is whether an energy-only market can produce a stable equilibrium and give policymakers confidence that Resource Adequacy, Security and Systemic Security will prevail with high levels of VRE. This involves examining missing money, missing markets, incomplete markets, shrinking markets and misinformed markets.

\section{$2.1 \quad$ Missing money}

The concept of Resource Adequacy in energy-only markets vis-à-vis administratively determined reliability constraints is well understood in energy economics (see Stoft, 2002; Besser et al. 2002; Oren, 2003; Bidwell \& Henney, 2004 amongst many others ${ }^{13}$ ). Entire editions of academic journals have been devoted to the topic. ${ }^{14}$ Literature on Resource Adequacy in energy-only markets can be loosely traced back to von der Fehr and Harbord (1995) who noted indivisibility of plant capacity, long construction lead-times, lumpy plant entry, investment tenor and policy uncertainty make merchant generation investments unusually risky. First contributions describing difficulties investing in merchant peaking plant in energy-only markets include Doorman (2000), De Vries (2002) and Stoft (2002). Resource Adequacy became a mainstream issue with Peluchon (2003), Roques et al. (2005), Hogan (2005), Cramton \& Stoft (2006), Joskow (2006), Finon \& Pignon (2008), Simshauser (2008), Finon (2008) amongst others cataloguing risks to timely entry and supply-side structural faults; first in Europe, then the US and Australia.

In theory, energy-only markets can clear demand reliably and provide suitable investment signals for requisite new capacity (Schweppe et al. 1988). But energy-only market theories are based upon equilibrium analysis and in practice electricity markets can be off equilibrium for extended periods of time (de Vries \& Heijien, 2008; Hirth et al. 2016). A long list of explicit and implicit assumptions underpin the theory including unlimited market price caps, limited political \&

\footnotetext{
${ }^{11}$ The Council of Australian Governments 'Energy Council' commissioned the Finkel Review in response.

${ }^{12}$ By 'systemic risk' I am referring to the risk of a large market participant experiencing financial distress through adverse wholesale spot market price exposures, in turn resulting in cascading failures of other market participants (analogous to systemic risks to banking systems during a financial crisis).

${ }^{13}$ See also Neuhoff et al. 2004; de Vries et al. 2004; Wen et al. 2004; Hogan, 2005; Bushnell, 2005; Roques et al. 2005; Cramton and Stoft, 2006; Joskow, 2006; Simshauser, 2008; Finon, 2008, 2011; Hogan 2013; Cramton, Ockenfels \& Stoft, 2013; and Spees et al. 2013.

${ }^{14}$ See for example Utilities Policy Volume 16 (2008) or Economics of Energy \& Environmental Policy Volume 2 (2013).
} 
regulatory interference, active demand-side participation, perfect forward markets and a largely equity capital-funded generation fleet able to withstand elongated price cycles.

As these assumptions are progressively relaxed it can be shown that energy-only markets with an administratively determined VoLL do not have a stable equilibrium (Bidwell \& Henney, 2004; Roques, 2008). Given substantial sunk costs and low marginal running costs, persistent generator bidding at marginal cost in an intensely competitive energy-only market will produce inadequate net revenues - known as the missing money problem (Cramton \& Stoft, 2006 ${ }^{15}$ ). Compounding matters are wholesale price caps set too low or over-enforced by regulatory authorities along with actions by System Operators which suppress legitimate price signals (Joskow 2008, Spees et al., 2013; Hogan, 2013, Leautier, 2016 and others ${ }^{16}$ ). Consequently, power markets are rarely in equilibrium.

This matters because capital-intensive merchant generators face rigid debt repayment schedules which of itself is unremarkable - but becomes problematic in the presence of incomplete forward derivatives markets (see Section 2.3). In consequence, the theory of spot electricity markets suffers from an inadequate treatment of how sunk capital is financed (Joskow, 2006; Finon, 2008; Meade \& O'Connor, 2009; Caplan, 2012; Nelson \& Simshauser, 2013). High levels of VRE is expected to amplify and complicate matters because such plant is subsidised in side-markets and priority dispatched (Nelson et al. 2012; Joskow, 2013; Newbery, 2015). Given negligible marginal running costs, merit-order effects arising from VRE became apparent in markets like Germany as early as 2008 (Sensfu $\beta$ et al. 2008).

Three broad remedies are typically suggested to deal with missing money viz. (1) introducing capacity markets, (2) raising VoLL, or (3) increasing Operating Reserves ${ }^{17}$ Each of these comes with problems. Introducing capacity markets represents a partial reversion to central planning which grinds against the decision to push market and investment risks away from consumers and to investors in the first place (Leautier, 2016). ${ }^{18}$ Raising VoLL compounds the risk of, and inability to distinguish, market power (Roques et al, 2005 and others ${ }^{19}$ ). And increasing Operating Reserves, which has the effect of expanding volumes and increasing the frequency of 'lower value VoLL events', may suffer similar problems. To be sure, none of these represent a choice between markets and intervention because each involve administratively-determined variables (Campton et al. 2013). ${ }^{20}$

Above all, electricity markets are characterised by several non-trivial market failures. Most hard and soft commodity markets clear under scarcity conditions via a combination of demand-bids

\footnotetext{
${ }^{15}$ See also Neuhoff et al. 2004; de Vries, 2004; de Vries et al. 2008; Bushnell, 2005; Roques et al. 2005; Joskow, 2008b; Finon, 2008; Simshauser, 2008; Joskow, 2013; Nelson \& Simshauser, 2013; Cramton, Ockenfels \& Stoft, 2013; Green \& Staffell, 2016; Keay, 2016.

${ }^{16}$ See also Besser et al. 2002; Oren, 2003; de Vries, 2003; Wen et al. 2004; Batlle \& Perez-Arriaga, 2008; Finon \& Pignon, 2008.

${ }^{17}$ On capacity markets see Bidwell \& Henney (2004); et al (2013); Green \& Staffell, (2016). On setting higher VoLL and Vertical Integration see for example Newbery (2006), Finon (2008), Simshauser (2010), Simshauser, Tian \& Whish-Wilson (2015). On increasing the requirement for operating reserves and enhancing reliability of supply see Hogan (2005, 2013).

${ }^{18}$ Hogan (2013) also notes there is no simple way to observe and measure delivery. Conversely, Cramton \& Stoft (2008) observe that even if capacity is overbuilt as a result of capacity mechanisms, the incremental cost to consumers is small because excess 'peaking plant' is the cheapest form of capacity (viz. an extra $10 \%$ of peak capacity may increase consumer costs by say $2 \%$ ). Additionally, Spees et al. (2013 pp15-16) observe that on balance capacity markets in the US have delivered good results in that they met their objective function, mobilised large amounts of low cost supply including Demand Response, energy efficiency, transmission interconnection, plant upgrades, deferred retirements and environmental retrofits.

${ }^{19}$ See also Besser et al, 2003; Oren, 2003; Cramton \& Stoft, 2006; Joskow 2008; Simshauser, 2008.

${ }^{20}$ A higher VoLL involves administratively determining a price cap to meet an administratively-determined reliability constraint. As Joskow (2013) notes, the entire logic of capacity markets starts with administratively-determined reliability criteria and involves administratively determining the quantity required to meet that constraint. And relying on FCAS involves administratively determining spinning reserve quantities in order to meet the reliability constraint. Thus each solution involves some form of administrative judgement, and in all cases, the risk of error - viz. exercise of market power with VoLL (Hogan, 2013); overinvestment with capacity markets (Leautier, 2016); or market power and excess reserves with FCAS - is ultimately borne by the customer.
} 
and supply-inventories. In electricity markets, large segments of real-time aggregate demand are price-inelastic and unable to react to scarcity conditions (Cramton \& Stoft, 2008, Batlle \& PerezArriaga, 2008; Roques, 2008; Finon \& Pignon, 2008). The supply-side is similarly inelastic in real-time because storage is costly. System Operators must therefore resort to non-price rationing and a regulator is forced to administratively determine VoLL. And participants in energy-only markets are unable to optimise the number of blackout events (i.e. VoLL) that produce stable equilibrium (Cramton et al. 2013).

\subsection{Missing Markets}

Electricity follows the laws of physics, not economics and consequently energy markets are an imperfect abstract of a complex physical system and prone to 'missing markets' (Newbery, 2015). Some are obvious; in the NEM there is no market for reserve capacity. ${ }^{21}$ Other missing markets relevant to rising VRE include Inertia, Fast Frequency Response, Ramping Duties and forward markets for Frequency Control Ancillary Services (FCAS).

A distinguishing characteristic of electricity is a moment-by-moment requirement to match supply and demand. Maintaining continuous electrical flows through a large interconnected power system requires high levels of coordination (MacGill, 2010). While real-time power (MW) is the primary service, FCAS are required to ensure a reliable and high quality power supply (Ela et al. 2012). The purpose of FCAS are to deliver accurate (1) Voltage, required by consumer appliances, and (2) Frequency ${ }^{22}$, required by synchronous generators (Stoft, 2002). Any supply-demand imbalance is first signalled by adverse deviations in Frequency. ${ }^{23}$ Frequency instability is therefore an outcome, and an indicator of, a disturbance event (Agranat et al. 2015).

By way of brief background, power is generated at a single synchronised AC Frequency measured in cycles per second or Hertz $(\mathrm{Hz})$. In the NEM, thermal generators synchronise to the grid at 50 cycles per second $(50 \mathrm{~Hz})$ meaning the fleet of turbines all rotate at exactly the same speed (i.e. 50 cycles $x 60$ seconds $=3000$ RPM for large steam turbines). It is vitally important that Frequency is maintained as close to $50 \mathrm{~Hz}$ as possible. Material deviations in the demandsupply balance for even a few seconds can send Frequency outside tolerable limits, at which point generators disconnect themselves to avoid damage ${ }^{24}$, potentially culminating in the collapse of a power system (Green \& Staffell, 2013).

Multiple FCAS markets exist to achieve delivered power at an accurate Frequency and are typically defined according to response speed and capability of existing conventional generators (Neuhoff et al., 2016). ${ }^{25}$ Australia's NEM is somewhat unique amongst restructured electricity markets with its centrepiece being a single platform involving a real-time mandatory gross pool spot electricity market and eight FCAS spot markets, co-optimised across five imperfectly interconnected regions with 5-minute dispatch resolution (MacGill, 2010). A single System Operator coordinates all regions and markets, and again uniquely, without a formal day-ahead market ${ }^{26}$ or capacity market (Riesz et al. 2015). The NEM's eight FCAS spot markets are organised into a Regulation market and three Contingency markets for raise and lower services, viz. (i) Regulation FCAS, (ii) 6-second Contingency, (iii) 60-second Contingency (iv) 5-minute

\footnotetext{
${ }^{21}$ This is of course an intentional design aspect of the NEM. In its place is a very high VoLL, currently $\$ 14,000 / \mathrm{MWh}$.

${ }^{22}$ Frequency is the rate at which Alternating Current alternates. In the NEM, AC completes one cycle 50 times per second (50 Hertz). Other markets such as the USA operate at 60 Hertz.

${ }^{23}$ It is also signalled by Voltage but this section is focused on Frequency. For further details on NEM Voltage procurement, see AEMO at https://www.aemo.com.au/-/media/Files/PDF/Guide-to-Ancillary-Services-in-the-National-Electricity-Market.ashx (accessed February 2017).

${ }^{24}$ As Agranat et al. (2015) note, low Frequency events can lead to the overheating of generators.

${ }^{25}$ Different markets define contingency reserves differently depending on the type of installed capacity, the nature of events they are required to respond to and the timeframes over which they respond and how such services are activated (Riesz et al. 2015). For example, Rivard \& Yatchew (2016) note that in Ontario, contingency reserves (known as operating reserves) are organised into 10minute synchronised, 10-minute non-synchronised, and 30-minute non-synchronised reserves.

${ }^{26}$ Although the Market Operator does produce a continuously updating $40 \mathrm{hr}$ pre-dispatch forecast.
} 
Contingency FCAS services. ${ }^{27}$ Generators manage their own unit commitment and other intertemporal scheduling constraints. Furthermore, FCAS markets are not simply recovered from consumers, but on the basis of 'causer pays'. ${ }^{28}$

Regulation FCAS are provided by generators to the System Operator using Automatic Generation Control (effectively real-time altering of MW output in line with small demand fluctuations inbetween 5-minute dispatch intervals) and serve to maintain Frequency within a tight range $(49.85-50.15 \mathrm{~Hz})$ for $99 \%$ of time (see Figure 1). Contingency FCAS deal with the remaining $1 \%$ of time involving non-trivial Frequency deviations arising from unexpected breakdowns of large generators, network elements or block-loads. Such conditions require a more substantive response than Regulation FCAS because Frequency will deviate beyond the usual range - the most common occurrence involving the loss of a large generator which may see Frequency fall to $49.5 \mathrm{~Hz}$ as Figure 1 notes.

When a supply-side disruption occurs, the speed that Frequency falls (i.e. the Rate of Change of Frequency or RoCoF) is crucially important (Keeratimahat et al. 2016). The slower the RoCoF, the easier deviations are to arrest (Agranat et al. 2015). Synchronous generators have a store of kinetic energy due to the rotational momentum in their rotors. Weighing between 106-233t $+{ }^{29}$, spinning at 3000RPM and being electrically coupled to the power system means that rotation Frequency has some initial 'Inertia'. Any change to Frequency from a disturbance event will first meet resistance from this passive physical response (Riesz et al. 2015). Inertia services are valuable for maintaining Frequency but historically has been supplied in such abundance that no formal market was considered necessary. 'Inertia' is therefore a missing market.

\footnotetext{
${ }^{27}$ That is, the 8 markets comprise both (1) raise, and (2) lower markets for each of the 4 services.

${ }^{28}$ For example, generators are responsible for 'Contingency Raise' services (since plant outages generally cause the requirement in the first place), while Loads are responsible for 'Contingency Lower' services. Regulation Raise and Lower is based on how participants have contributed to Frequency instability. This causer pays approach sends a superior signal to market participants, it can be the case that over- and under-frequency contributions by a single generator within a 5-minute dispatch interval cancel each other out and hide Frequency deviations caused by a VRE (or thermal) generator. See Riesz et al. (2015) for further details.

${ }^{29}$ The rotating mass of Queensland 350MW generators are 106t (i.e. High \& Intermediate Pressure turbine 16t, Low Pressure turbine $50 \mathrm{t}$ and generator $40 \mathrm{t}$ ). The rotating mass of the 500MW generators in Victoria and 660MW generators in New South Wales are $217.5 \mathrm{t}$ and $232.8 \mathrm{t}$, respectively.
} 
Figure 1: Frequency deviation

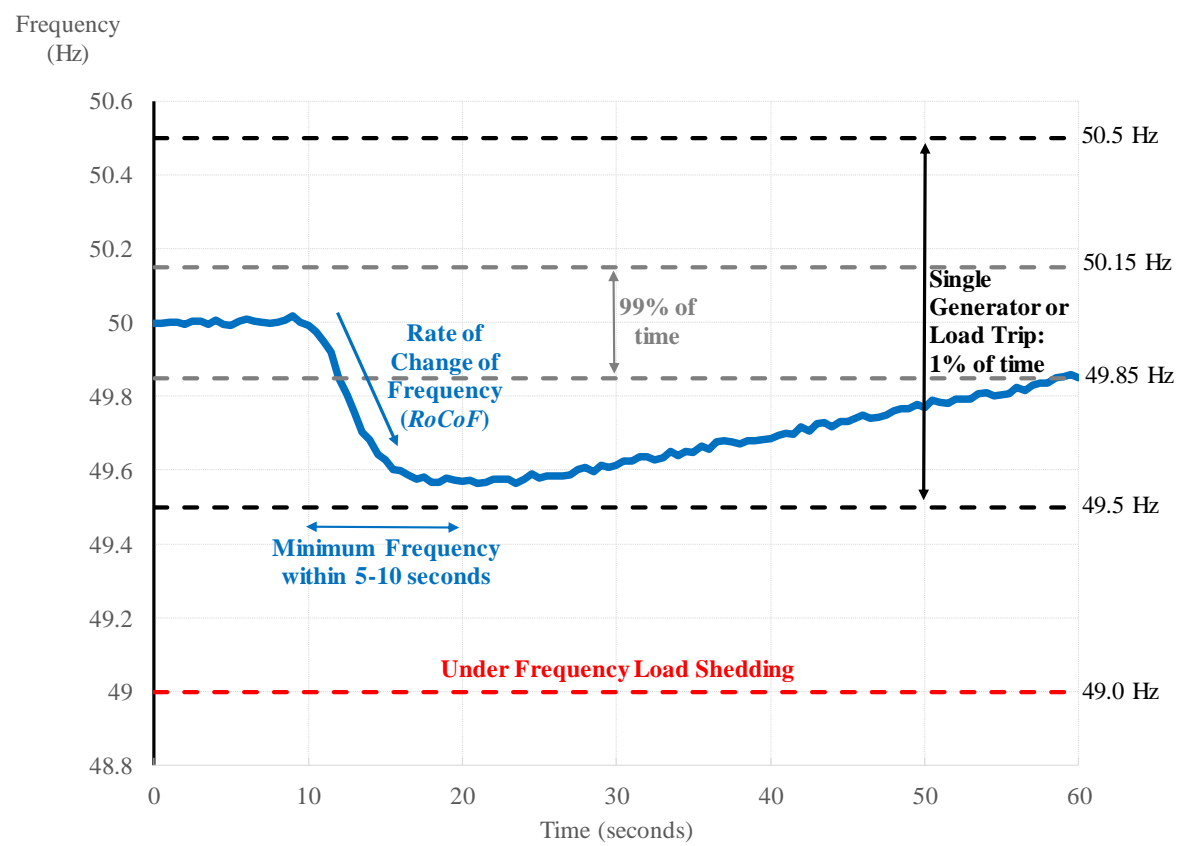

A rapid response is required to arrest Frequency decline - minimum Frequency must be achieved within 5-10 seconds in order to avoid system collapse (Ela et al. 2012). In the NEM, apart from Inertia the first market response comes from 6-second FCAS. Synchronous generators usually have store of excess steam and latent energy in boilers which can be released to give an initial boost of output (essentially additional output not associated with 'additional fuel' to boilers). 6second resources are deployed without System Operator intervention to enable an orderly transition to 60 -second ${ }^{30}$ raise resources, which further stabilise Frequency and enable an orderly transition to 5-minute resources (Riesz et al. 2015). These collective resources restore the system back to its nominal $50 \mathrm{~Hz}$ Frequency over a 5-minute window (see Figure 1). If Frequency falls below 49Hz 'automated' non-price load shedding, known as Under Frequency Load Shedding, occurs in order to avoid power system collapse. ${ }^{31}$

A challenge of rising VRE is how Frequency will be managed. NEM VRE sources (solar and wind) are currently connected asynchronously to the power system with power electronic interfaces and are not physically coupled to system Frequency. They do not provide Inertia during Frequency deviations (Agranat et al. 2015). Furthermore, NEM-installed VRE plant are not designed to provide FCAS raises services (MacGill, 2010). Consequently, as synchronous thermal plant exit to make way for asynchronous VRE, one can expect the supply of Inertia and FCAS raise to fall (MacGill, 2010; Hogan, 2013; Green \& Staffell, 2013; Newbery, 2015). And as the supply of Inertia falls, 6-second FCAS resources may become inadequate to arrest Frequency deviations. A market for Fast Frequency Response (i.e. 1 second) may be required (Agranat et al. 2015). Rising levels of stochastic VRE output may also exceed demand uncertainty, meaning existing levels of Frequency Regulation resources may become inadequate (Riesz et al. 2015).

With high levels of solar PV comes greater requirements for Ramping Duties; solar PV output naturally declines in the evening which coincides with rapidly rising household peak demand -

\footnotetext{
${ }^{30} 6$-second \& 60-second FCAS are usually operated by governor response or load shedding, and are triggered by Frequency moving outside the normal operating band.

${ }^{31}$ In the NEM, non-price load-shedding or Under Frequency Load Shedding, a highly automated sub-second event, can generally be relied to arrest a 'Rate of Change of Frequency' (RoCoF) of up to 3.5Hz per second. In 2016, South Australia experienced a RoCoF of $6.25 \mathrm{~Hz}$ per second which resulted in a system collapse.
} 
this combination may produce dramatically steeper rises in intra-period residual system demand. As with Inertia, Ramping capability has been supplied in such abundance no market was considered necessary. Given the experience of solar-rich jurisdictions like California, one may expect the demand for Ramping Duties in the NEM to increase considerably while the exit of thermal plant means supply will fall. Consequently, a market for Ramping Duties also represents a missing market.

Counterintuitively, the NEM's overall quantity of FCAS services dispatched has remained static ${ }^{32}$ with procurement undertaken on a global- (not regional-) basis as VRE is rising. ${ }^{33}$ Hogan (2013) notes system reliability improves by increasing quantities of FCAS dispatched and while the importance of Operating Reserves have long been known, requirements are frequently given simplified consideration (Hogan, 2005). Spot FCAS prices also appear inefficiently low in equilibrium, which as Newbery (2015) explains forms part of the missing money. Conversely when thermal plant exits, the price of FCAS raise services rise to non-trivial levels. ${ }^{34}$ This tends to suggest volumes procured, procurement location, and co-optimised price setting requires review.

Finally, a crucial missing market in the NEM is a forward FCAS market. It is crucial because spot FCAS market revenues are unbankable, and this alone reinforces development of VRE plant that maximise spot electricity output with no FCAS capability - real or synthetic.

In summary, as VRE enters the demand for Inertia, Fast Frequency Response, Ramping Duties and FCAS quantities rise while simultaneously, exit of thermal plant means supply will fall. Compounding matters, there is no forward market signalling emerging imbalances or looming requirements to incorporate FCAS capability (real or synthetic) into new entrant VRE plant capacity.

\subsection{Incomplete Markets}

Energy markets are never complete or free of market failures (Hirth et al. 2016). A market failure inherent in energy-only markets is their inability to deliver the requisite mix of derivative instruments required to facilitate efficient plant entry (Hansen, 2004; Chao, Oren and Wilson, 2005; Meade and O'Connor, 2009; Meyer, 2012). As Finon (2011) explains, the canonical model in deregulated energy-only markets was the Merchant Power Producer, a stand-alone generator that sold its production into spot and short-term forward markets, underpinned by long-dated nonrecourse project finance. In the early phases of the global restructuring and deregulation experiment, a vast fleet of merchant plant was banked on this basis (Joskow, 2006; Finon, 2008). ${ }^{35}$

But recurring economic damage to merchant generator Profit \& Loss Statements, a product of missing money, began to take its toll on project bank risk tolerances and credit metrics (Simshauser, 2010). By 2005 more than 110,000MW of merchant plant in the US, much of the Australian merchant fleet and some high profile plant in the UK (e.g. Drax) experienced financial distress or bankruptcy (Finon, 2008; Nelson \& Simshauser, 2013). Consequently, the canonical model became un-bankable in the absence of long-term (i.e. 10+ years) contracts. There is now

\footnotetext{
${ }^{32}$ In the NEM FCAS is determined dynamically in each 5-minute interval, but the parameters have remained static (viz. the single largest contingency event (loss of the largest generator, for example).

${ }^{33}$ FCAS is procured globally across regions subject to network constraints. In periods of higher variability, FCAS regulation automatically rises from the typical set point of $130 \mathrm{MW}$ to as much as $230 \mathrm{MW}$ (in 60MW increments) to maintain Frequency. But threshold quantities (typically around 990MW in aggregate) have remained static as VRE is rising.

${ }^{34}$ In QLD, NSW and VIC, the spot electricity market forms $>99.7 \%$ of total revenue. More recently, 'FCAS raise' services in SA have risen to a surprisingly large 5-7\% of market revenues - the point being that FCAS raise services provided by thermal plant have almost no value until plant exit, at which point they become extremely valuable.

${ }^{35}$ This included 230,000MW in the US, 13,000MW in Australia and more than 6000MW of new plant in the UK. See Joskow (2006), Finon (2008) and Simshauser (2010) for details.
} 
considerable evidence to support the notion that timely plant entry on a purely merchant basis is intractable ${ }^{36}$ in energy-only markets (Joskow, 2006; Howell, Meade \& O'Connor, 2010; Caplan, 2012; Nelson and Simshauser, 2013).

Long-dated contracts have become a pre-condition for project finance, and while Australia's NEM is noted for favourable forward market liquidity ${ }^{37}$, activity spans 3 years - well short of optimal financing that facilitate efficient ex-ante investment commitment, viz. 12-year semipermanent project debt set within 18-25 year structures. Forward markets have failed to calibrate beyond 3 years because competitive Retailers cannot afford to hold hedge portfolios dominated by inflexible long-dated contracts when large components of their customer book switch supplier every 2-3 years as Figure 2 illustrates (i.e. large Commercial \& Industrial (C\&I) customers are now signing, on average, contracts of just 22 months duration). The short-tenor bias of merchant retailers can be traced to excessive retail-level competition, demand uncertainty and risks of being undercut by new entrant retailers with short-dated portfolios (Newbery, 2006 and others ${ }^{38}$ ).

Figure 2: $\quad$ NEM average C\&I contract tenor: 2006-2016 term-to-maturity

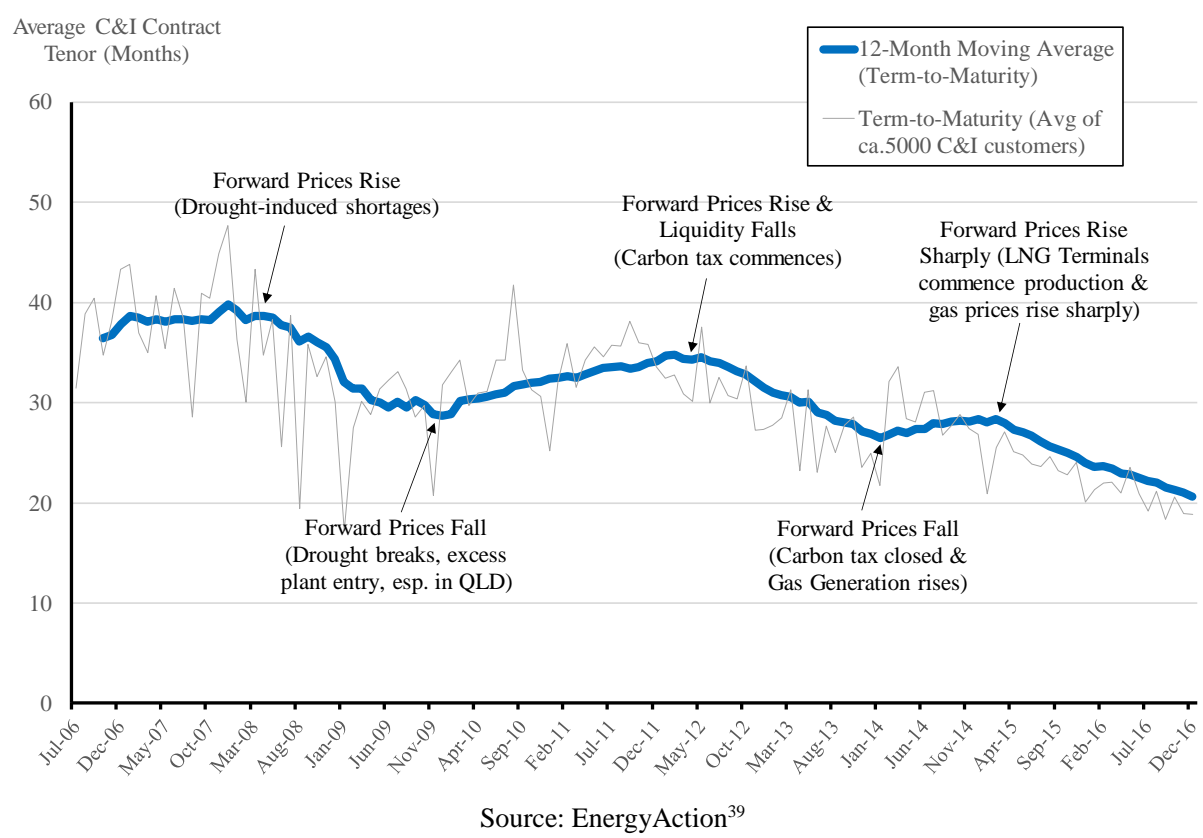

\subsection{Shrinking markets}

An under-researched aspect of the NEM is the impact of rising VRE on the supply of forward derivative contracts and in particular, where transmission amongst regions is imperfect. Under normal conditions, NEM derivative market turnover runs at multiples of physical spot electricity market (Chester, 2006; Howell, Meade \& O'Connor, 2010) although there have been sporadic episodes of hedge contract shortages in certain regions (Anderson et al. 2007 ${ }^{40}$ ).

\footnotetext{
${ }^{36}$ To be clear, plant will eventually enter on a merchant basis if prices are high enough. But the political economy of such prices makes this problematic.

${ }^{37}$ See for example Chester (2006); Anderson et al. (2007); Howell, Meade \& O’Connor (2010); and most recently, Simshauser et al. (2015, Appendix 3 and Figure C.1 on p.54).

${ }^{38}$ See also Green, 2006; Anderson et al. 2007; Finon, 2008; Simshauser, 2010; Howell, Meade and O’Connor, 2010

${ }^{39}$ Based on approximately 5000 C\&I customers. Thanks to Michael Fahey (EnergyAction) for providing this data.

${ }^{40}$ See also Simshauser, Molyneux \& Shepherd (2010) on episodes of hedge contract supply shortages in the NEM.
} 
Various Australian regulatory authorities had argued Vertical Integration would drive reductions in market liquidity. ${ }^{41}$ But the evidence is that at the height of vertical M\&A activity (2005-2012) contract liquidity expanded (Simshauser et al., 2015). Structural imbalances between the retail and generation units of vertical utilities drives activity in the same way that generator market power of vertical utilities can be muted by such imbalances (Bushnell et al. 2007; Mansur 2007). What has had an adverse effect on derivative market liquidity is climate change policy volatility (Simshauser et al. 2015; Nelson \& Orton, 2016).

When thermal plant exit in response to rising VRE, additional transmission interconnection to adjacent region(s) can help maintain security of supply. But unless interconnection results in a single region being formed, all else equal, the introduction of VRE and the exit of thermal plant will change the supply mix of asset-backed or 'primary-issuance' intra-regional hedge contracts, viz. falling firm swap and cap contracts, and rising non-firm VRE contracts.

Unlike merchant coal and gas plant which sell firm swap and cap contracts, VRE plant are typically underwritten by long-dated, non-firm, joint-product Power Purchase Agreements (PPAs) comprising (underlying) variable power and (headline) Renewable Certificates. And in a more recent trend, sub-national governments have originated policies that underwrite VRE plant via non-firm, joint-product Contracts-for-Differences (CfDs).

Non-firm PPAs and CfDs are not perfect substitutes for firm swaps and caps, the reasons for which are axiomatic. With moderate levels of VRE, or perfectly interconnected regions, this may pose little problem. But as non-firm VRE instruments form a progressively larger share of the forward market via the ongoing exit of thermal plant, there must be some tipping point whereby a level of instability emerges in hedge markets via shortages of primary-issuance firm swaps and caps required by firms with retail exposures.

Non-firm VRE contracts are not good substitutes for firm contracts, but some nominal component can be utilised against peak load in large, diversified Vertical Retailer hedge books. But government-initiated CfDs may be problematic if not designed (nor intended) for secondary market trade. Along with the gradual evaporation of firm hedge contract supply as thermal plant exit, government-initiated CfDs can have the (unintended) effect of extracting the replacement non-firm contract supply - potentially culminating in hedge contract supply shortages and foreclosing competitive $2^{\text {nd }}$ tier Retailers.

\subsection{Misinformed markets}

Just as Resource Adequacy meets resistance in energy-only markets, Renewable Targets meet similar resistance due to missing money and incomplete markets. Renewable Targets place a liability on Retailers to purchase a set percentage from renewable sources. VRE plant require long-dated PPAs written by counterparties with investment-grade credit ratings to facilitate finance and therefore, entry. Vertical Retailers with investment-grade credit ratings have two broad customer classes; loyal Mass Market and non-loyal large C\&I customers. The latter are sophisticated buyers that switch supplier frequently, and may even purchase their own Renewable Certificates. Consequently, Vertical Retailers tend to acquit Renewable liabilities for loyal Mass Market customers via long-dated VRE PPAs but it would be highly irregular (and risky) for Vertical Retailers to write 15 -Year VRE PPAs for their non-loyal C\&I customers ${ }^{42}$. Renewable Target policies thus face market resistance because Vertical Retailers can only reasonably underwrite so much VRE plant before their own Balance Sheets become stressed (Neuhoff et al. 2016). And very few $2^{\text {nd }}$ Tier Retailers have investment-grade credit ratings. Dargue $\&$ Koenders

${ }^{41}$ Such criticism came from (i) the Australian Energy Regulator, (ii) the Australian Energy Market Commission, (iii) the Australian Competition and Consumer Commission and (iv) the Australian Government (various references spanning 2011-2014) in spite of quantitative evidence to the contrary. See See Simshauser, Tian \& Whish-Wilson (2015, especially Section 2).

${ }^{42}$ Recall from Figure 2 these customers sign contracts for, on average, 22 months. 
(2016) estimate the underlying C\&I PPA gap could be as much as 7,000 GWh out of 15,100 GWh new VRE required as Figure 3 notes:

Figure 3: Vertical Retailer Renewable Certificates vs Total Market

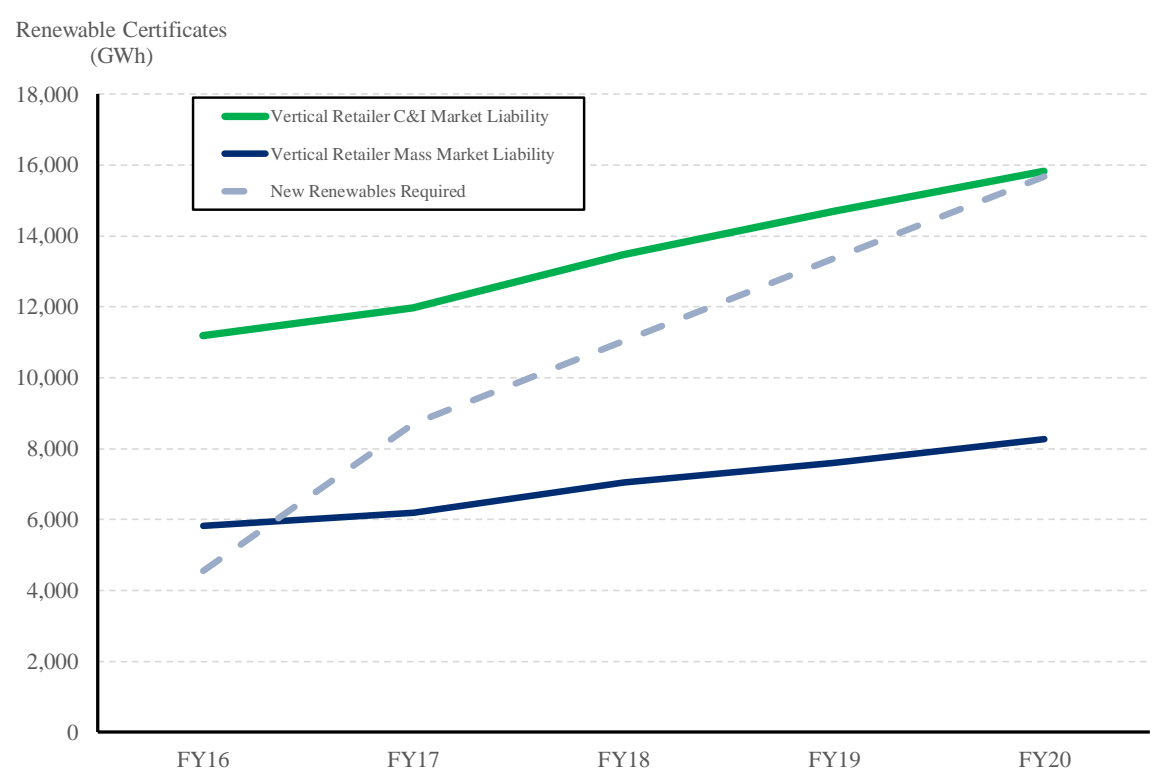

Sub-national governments recognised these shortfalls and many constructed 'reverse auctions' involving various forms of CfDs to bridge the Renewables contracting gap. While a ca.2300MW shortage was estimated, sub-national government CfDs totalling $3000 \mathrm{MW}$ were telegraphed to the market. ${ }^{43}$

Section 2.4 explained government-initiated CfDs can produce a shrinking market and undersupply of intra-regional hedge contract capacity. But the market can become misinformed and regions 'overloaded' if non market-participants (i.e. governments) over-rely on Levelised Cost of Electricity (LCoE) during CfD execution.

Used carefully, LCoE estimates are essential inputs to system planning. LCoE estimates are not, however, outputs for investment commitment. Setting policy and executing CfDs on the basis of LCoE will eventually produce distortionary outcomes, expose taxpayers to unnecessary losses, and produce misinformed markets.

The physical properties of electricity are largely homogeneous over space and time. But as Hirth et al. (2016) explain, from a market perspective there is rich price variation over time, space and lead time-to-delivery making the traded commodity a heterogeneous good. ${ }^{44}$ As they explain, the economic value of plant output is not identical and assuming otherwise introduces two biases; base plant is favoured over peak, and stochastic plant is favoured over dispatchable plant. As a stand-alone metric, $\mathrm{LCoE}$ is flawed because it treats technology output as homogeneous products

\footnotetext{
${ }^{43}$ As at March 2017, 750MW had been executed. The QLD Government had executed 150MW of CfDs and telegraphed a further 400MW. NSW Government telegraphed 250MW of CfDs. ACT had executed 600MW of CfDs. The VIC Government had telegraphed up to $1500 \mathrm{MW}$ of CfDs by 2020 and a further $3900 \mathrm{MW}$ by 2025 . There are also a number of PPAs (VIC Government tenders totalling 171MW for Renewable Certificates, and Sydney Northwest Metro totalling 52MW) but these appear to be wellconstructed, non-distortionary, government contracts designed to meet retail liabilities. Similarly, at the time of writing the Qld Government was working on 'recycling' its $150 \mathrm{MW}$ CfDs back into the secondary market in order to minimise any such distortions ${ }^{44}$ Heterogeneous goods satisfy three conditions; (1) an inability to arbitrage (i.e. storage is costly); (2) no single efficient technology exists (e.g. in electricity planning there is typically an efficient combination of base, intermediate and peak plant); and (3) nonhorizontal supply costs (e.g. electricity merit-order supply curves are always upward sloping). As Hirth et al. 2016, p.5) explain, storage links electricity in time, transmission links electricity in space and flexibility (i.e. balancing services) links electricity in leadtime.
} 
as if governed by the law of one price (Joskow, 2011; Mills \& Wiser, 2012; Edenhofer et al. 2013).

In real-time, the law of one price does apply; output from wind and solar are good substitutes for thermal generation. However, each year there are 105,120 NEM prices ${ }^{45}$ and when demand is higher than forecast, all else equal, dispatchable generators increase output and receive a higher average price. Conversely, stochastic generators rarely reduce output in periods of oversupply, and hence sell disproportionately at lower prices (Dargue \& Koenders, 2016; Hirth et al. 2016).

Furthermore, as VRE technologies move from niche to material market shares, deployment success becomes a significant driver of market value (MacGill, 2010; Joskow 2011; Nicolosi, 2012; Mills \& Wiser 2012; Hirth, 2013). Green \& Staffell (2016) note this is amplified when thermal plant fails to exit. Consequently, the market value of VRE is affected by 'correlation effects', 'merit-order effects' and 'price-impression effects' (see Section 4). ${ }^{46}$ Tangentially, as VRE market share increases Nicolosi (2012, pp.35-38) identifies a 'utilisation effect' and a 'flexibility effect' on thermal plant whereby their annualised capital costs increase as the annual capacity factor of such plant declines, and an increasing incidence of negative prices.

\section{On the stability of the spot market}

In order to analyse the stability of spot markets with rising levels of VRE, the NEMESYS-PF Model has been used. NEMESYS-PF formally integrates a Corporate \& Project Finance Model with a single-year dynamic, partial equilibrium, security-constrained unit commitment simulation Model with half-hourly resolution and price formation based on a uniform, first-price auction clearing mechanism. As with Bushnell (2010), the Model assumes perfect competition and essentially free entry to install any combination of capacity that satisfies differentiable equilibrium conditions, with VRE plant output being determined exogenously. Model details are contained in Appendix I.

\subsection{Generalised long run marginal cost estimates}

Salient features of the present exercise are as follows. Thermal plant (Coal, CCGT, OCGT) are Balance Sheet-financed (gearing ca.40-47\%, BBB credit rating) and VRE plant (Wind, Solar) are Project Financed (ca.80\% debt) and underpinned by investment-grade PPAs. Relevant assumptions are outlined in Appendix I. Generalised long run marginal cost estimates from the Model are presented in Figure 4, and are a high-resolution LCoE incorporating debt-finance and taxation variables. Gearing levels for each plant are displayed at the base of each bar. Thus in Figure 4, Coal has $42 \%$ gearing and a generalised long run marginal cost of $\$ 55.56 / \mathrm{MWh}$ comprising Unit Fuel Costs of \$16.62/MWh, O\&M Costs of \$8.74/MWh, Debt and Interest Costs of $\$ 1.90$ and $\$ 6.04 / \mathrm{MWh}$, and Taxation and Equity Costs of $\$ 5.01$ and $\$ 17.25 / \mathrm{MWh}$, respectively.

\footnotetext{
${ }^{45}$ In the NEM, dispatch has 5-minute resolution and thus 105,120 dispatch intervals each year.

${ }^{46}$ Taking solar PV as an example, the correlation effect starts positive due to the diurnal correlation between solar resources and electricity demand. The merit-order effect is a well-known economic result; the price of a good falls as supply is increased. As thermal plant exits, merit-order effects can be expected to unwind but the stochastic nature of VRE plant means a price-impression effect persists. In an expansive literature review on the topic, Hirth (2013) reveals that as solar is progressively increased from $0 \%$ to $10-15 \%$ market share, its relative value drops from slightly more than $100 \%$ of base prices to $70 \%$ (i.e. price-impression effect). And as wind output is increased from $0 \%$ to $30 \%$ market share, its relative value drops to $70 \%$ of base prices.
} 
Figure 4: Generalised long run marginal cost by technology

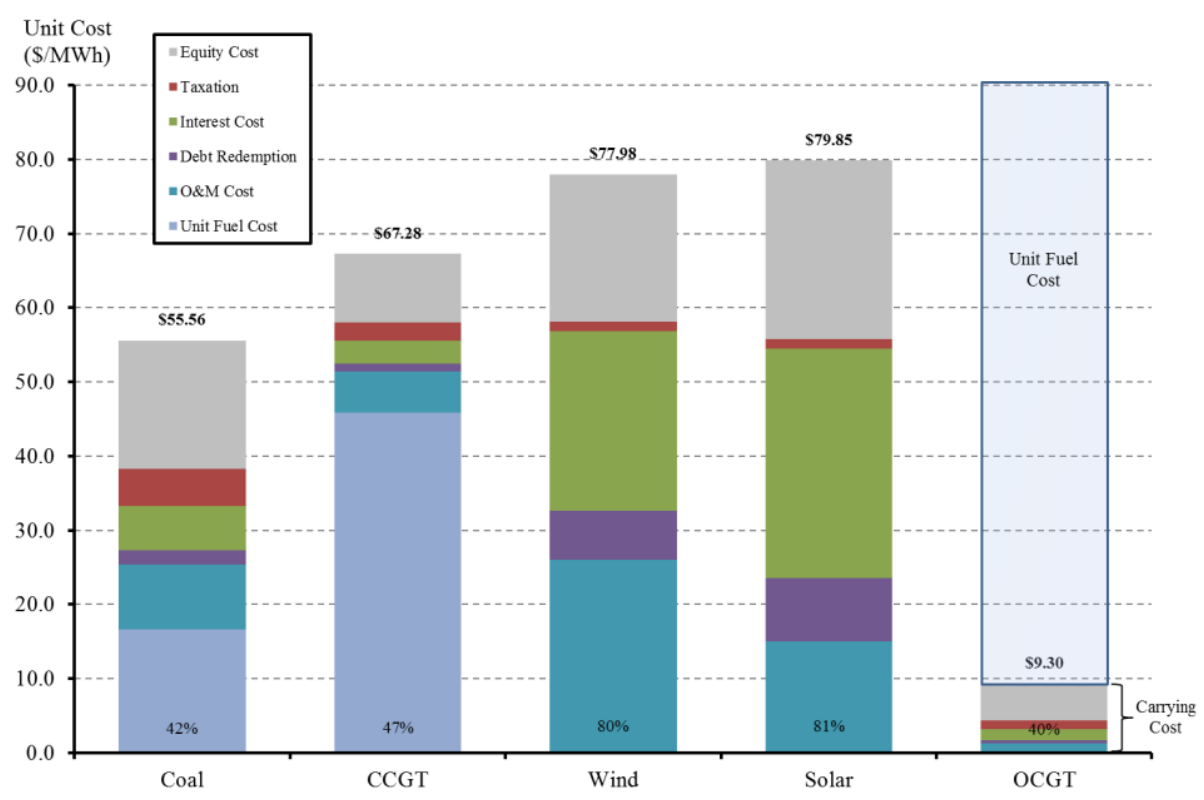

\subsection{Base Case}

The Base Case load curve utilises QLD 2016 data (9097MW peak demand, 54900GWh energy demand, ex-1500MW rooftop solar PV). An own-price elasticity estimate of -0.10 is used in all scenarios. The QLD system is modelled without interconnection to neighbouring NSW. The perfectly divisible plant stock is optimised and includes a starting reserve margin of $13 \%$ to ensure the NEM's administratively determined reliability constraint of no more than $0.002 \%$ Lost Load is met. Plant are initially assumed to be perfectly available with no ramp rate constraints. Availability assumptions are relaxed in Section 5. Coal plant minimum loads are assumed to be $40 \%$ of Maximum Continuous Rating, and VRE plant are constrained-off if necessary (i.e. coal 'min gen' is priority dispatched).

One crucial deviation from the NEM's energy-only market design has been incorporated in the present Modelling exercise; there are no VoLL events, instead Boiteux capacity payments are paid to all dispatchable plant at a rate exactly equal to the carrying-cost of an OCGT (see Fig.4). This ensures that in the Base Case, the market 'clears financially' and has two primary benefits; (1) it removes noise associated with market power and the optimal value, and number of, VoLL events; and (2) it allows impacts of rising VRE to be isolated. As in the NEM, Renewable Certificates are incorporated for VRE plant with the value equal to the differential between the market value of output, and generalised long run marginal costs estimates. Base Case results, where the power system has been optimised without utility-scale VRE plant, are presented in Table 1. 
Table 1: $\quad$ Production duties and financial position of plant - Base Case

\begin{tabular}{|c|c|c|c|c|c|c|c|c|c|}
\hline & Generation & $\begin{array}{c}\text { Capacity } \\
\text { (MW) }\end{array}$ & $\begin{array}{c}\text { Production } \\
(\mathrm{GWh})\end{array}$ & $\begin{array}{l}\text { Fixed Costs } \\
\qquad(\$ \mathrm{~m})\end{array}$ & $\begin{array}{c}\text { Running Costs } \\
\qquad(\$ \mathrm{~m})\end{array}$ & $\begin{array}{l}\text { Resource Cost } \\
(\$ \mathrm{~m})\end{array}$ & $\begin{array}{l}\text { Avg Unit Cost } \\
\text { (\$/MWh) }\end{array}$ & $\begin{array}{c}\text { Market } \\
\text { Share }\end{array}$ & $\begin{array}{c}C F_{j}{ }^{i} \\
(\%)\end{array}$ \\
\hline 1 & Wind & 0 & 0 & 0 & 0 & 0 & 0.00 & $0.0 \%$ & 0.0 \\
\hline 2 & Solar & 0 & 0 & 0 & 0 & 0 & 0.00 & $0.0 \%$ & 0.0 \\
\hline 3 & Coal & 6,014 & 50,842 & 2,052 & 845 & 2,896 & 56.97 & $92.6 \%$ & 96.5 \\
\hline 4 & CCGT & 758 & 2,906 & 142 & 133 & 276 & 94.83 & $5.3 \%$ & 43.8 \\
\hline 5 & OCGT & 3,508 & 1,175 & 286 & 106 & 392 & 333.36 & $2.1 \%$ & 3.8 \\
\hline 6 & Total & 10,280 & 54,924 & 2,480 & 1,084 & 3,564 & 64.88 & $100.0 \%$ & 61.0 \\
\hline & & $\begin{array}{l}\text { Average } \\
\text { Spot Price } \\
\text { (\$/MWh) }\end{array}$ & $\begin{array}{c}\text { Spot Market } \\
\text { Revenue } \\
(\$ \mathrm{~m})\end{array}$ & $\begin{array}{c}\text { Capacity/RE } \\
\text { Payments } \\
(\$ / \mathrm{MW})\end{array}$ & $\begin{array}{c}\text { Capacity/RE } \\
\text { Payment } \\
(\$ \mathrm{~m})\end{array}$ & $\begin{array}{c}\text { Total } \\
\text { Revenue } \\
(\$ \mathrm{~m})\end{array}$ & $\begin{array}{c}\text { Resource } \\
\text { Cost } \\
(\$ \mathrm{~m})\end{array}$ & $\begin{array}{c}\text { Revenue } \\
\text { Shortfall } \\
(\$ \mathrm{~m})\end{array}$ & \\
\hline 7 & Wind & 43.40 & 0 & 0.00 & 0 & 0 & 0 & 0 & \\
\hline 8 & Solar & 51.59 & 0 & 0.00 & 0 & 0 & 0 & 0 & \\
\hline 9 & Coal & 47.33 & 2,406 & 9.30 & 490 & 2,896 & 2,896 & 0 & \\
\hline 10 & CCGT & 73.58 & 214 & 9.30 & 62 & 276 & 276 & 0 & \\
\hline 11 & OCGT & 90.19 & 106 & 9.30 & 286 & 392 & 392 & 0 & \\
\hline 12 & Total & 49.64 & 2,726 & 9.30 & 837 & 3,564 & 3,564 & -0 & \\
\hline 13 & System Avg Cost & 64.88 & & & $\downarrow$ & & & & \\
\hline 14 & Missing Money & 15.25 & & & $\$ 15.25 / \mathrm{MWh}$ & & & & \\
\hline 15 & Peak Price & 83.78 & & & & \multicolumn{3}{|c|}{ Base Price (time-weighted): } & 46.26 \\
\hline 16 & Shoulder Price & 52.59 & & & & \multicolumn{3}{|c|}{ Load-Weighted Avg Spot Price: } & 49.64 \\
\hline 17 & Off-Peak Price & 23.32 & & & & \multicolumn{3}{|c|}{ Avg Renewable Certificate Price: } & 0.00 \\
\hline
\end{tabular}

In Table 1, Lines 1-6 highlight 10280MW of plant is deployed including 6014MW of coal.

Resource Costs amount to $\$ 3,564 \mathrm{~m}$, System Average Cost is $64.88 / \mathrm{MWh}$ and the Capacity Factor $(\mathrm{CF})$ of the power station fleet is $61.0 \%$. Price and revenue parameters are presented in Lines 7-

17. The Load-Weighted Average Spot Price is \$49.64, and given System Average Costs of $\$ 64.88$ the missing money amounts to $\$ 15.25 / \mathrm{MWh}$. Missing money is eliminated via Boiteux capacity payments paid to each MW installed at a rate exactly equal to the carrying cost of OCGT plant $^{47}$ (i.e. \$9.30/MW, see OCGT in Figure 4). Note the time-weighted Base Price is $\$ 46.26 / \mathrm{MWh}$ (Line 15) - a result that will be used as a benchmark throughout this research.

Figure 5 presents a static equilibrium analysis based on the seminal works of Berrie (1967). The top chart highlights two Load Duration Curves, a Gross Load (i.e. net of 5\% rooftop solar PV) and Net Load (i.e. net of 35\% VRE output). The optimal plant mix is derived from the middle chart which extracts the LCoE results from Figure 4 and transposes these data into Marginal Running Cost Curves for the three thermal technologies. The points of intersection are transposed to the Load Duration Curve to identify the optimal mix of Base, Intermediate and Peak plant. The bottom chart shows the distribution of prices; recall there are no VoLL events, just three spot prices prevail in equilibrium, averaging \$46.26/MWh.

${ }^{47}$ In this instance, $\$ 9.30 / \mathrm{MW}$ x 10280MW $\div 54,924 \mathrm{GWh}=\$ 15.25 / \mathrm{MWh}$. Simshauser \& Ariyaratnam (2014 see Appendix) provide a mathematical proof. 
Figure 5: Static partial equilibrium (loads net of 5\% rooftop solar PV) Electricity Load

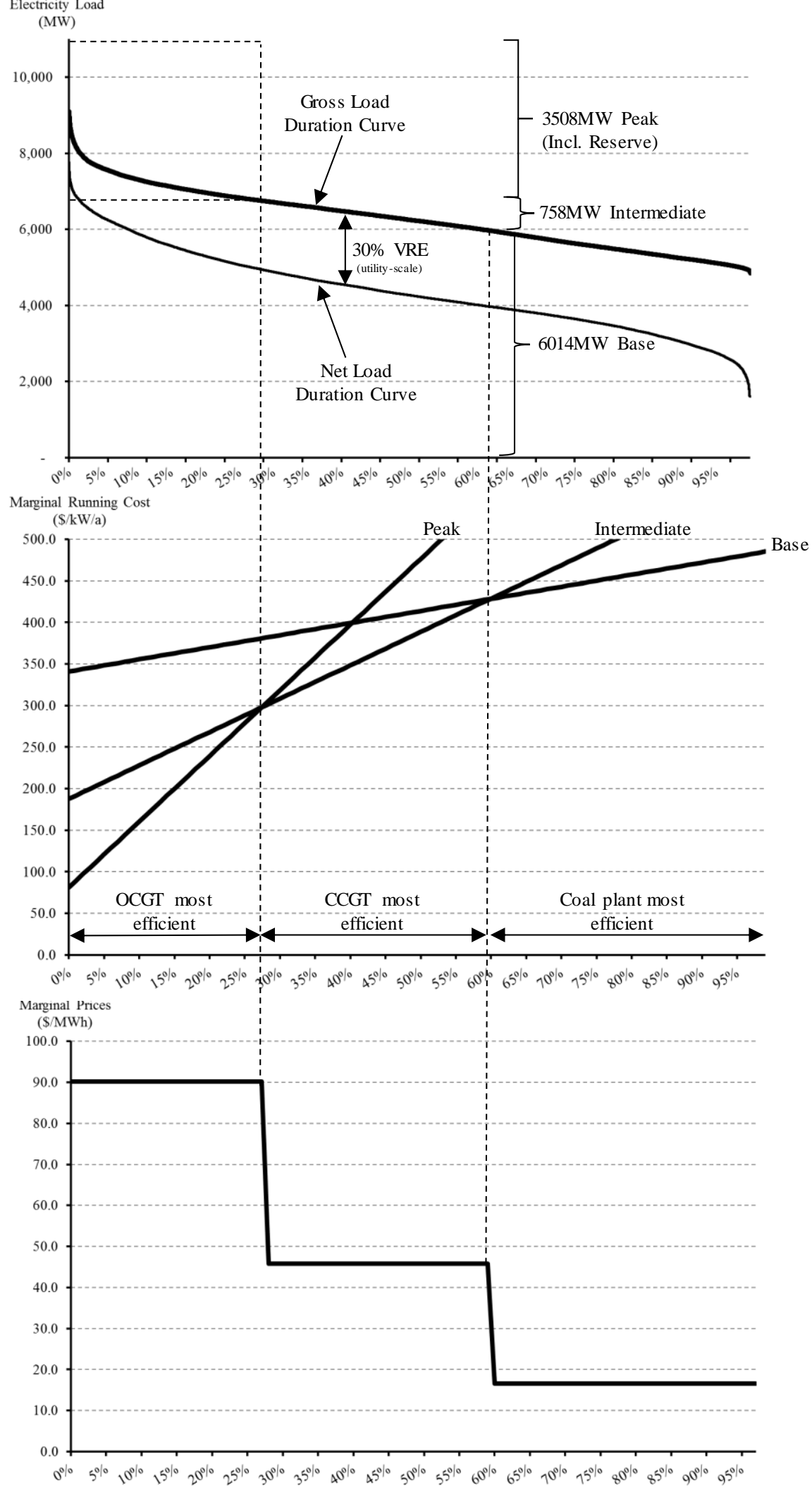

Time Exceeded Per Annum 


\subsection{Mid-term and long-term scenarios}

Utility-scale VRE is progressively introduced rising to $30 \%$ market share. Recall Gross Load is net of 5\% rooftop Solar PV - thus scenarios run from 5-35\% VRE (viz. 0-30\% utility-scale VRE plus 5\% small-scale VRE). Following Hirth (2013), two timeframes are analysed; Mid-Term and Long-Term and are distinguished by how the capital stock adjusts rather than time. In Mid-Term scenarios, thermal plant is held constant (Figure 6). In Long-Term scenarios, thermal plant adjusts perfectly; coal exits and gas plant enters while meeting reliability constraints (Figure 7).

\section{Figure 6: Mid-Term capacity for rising VRE (no plant exit)}

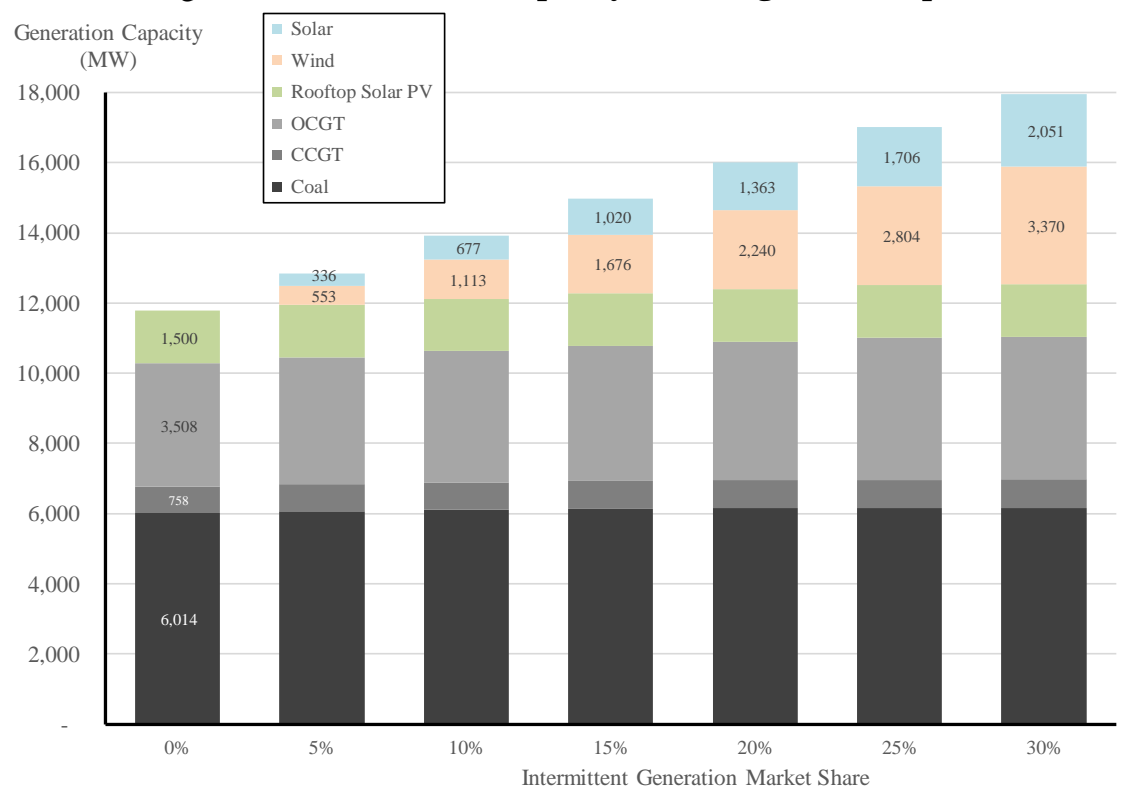

Figure 7: Long-Term capacity for rising VRE (thermal plant adjusts perfectly)

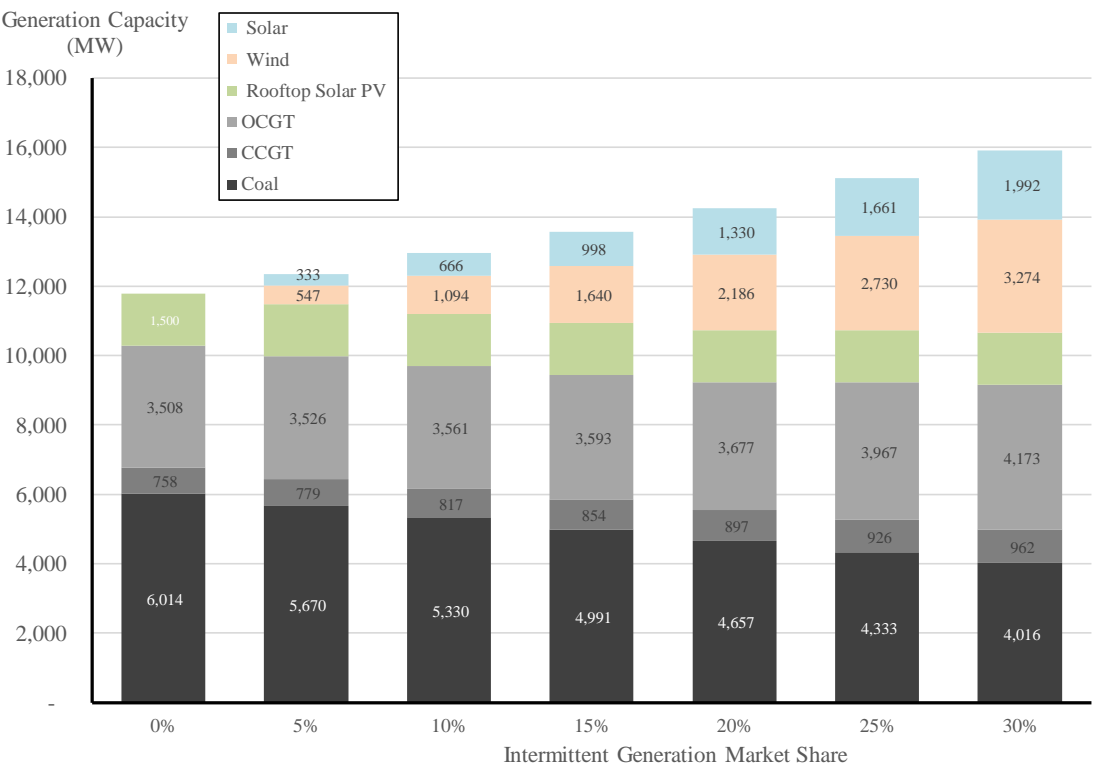

Mid- and Long-Term 30\% VRE scenarios are presented in Tables 2-3. In the Mid-Term (Table 2 ), no coal plant exits and Resource Costs rise to $\$ 4,579 \mathrm{~m}$ or $\$ 81.26 / \mathrm{MWh}$ (line 6) while Base Prices fall to $\$ 19.55 / \mathrm{MWh}$ (line 15). This result reflects an acute merit-order effect that cannot be 
remedied by capacity payments. ${ }^{48}$ However, VRE plant clear financially (Lines 7-8) via rising Renewable Certificate prices, averaging \$60.72/MWh (line 17).

Table 2: Mid-Term 30\% VRE scenario

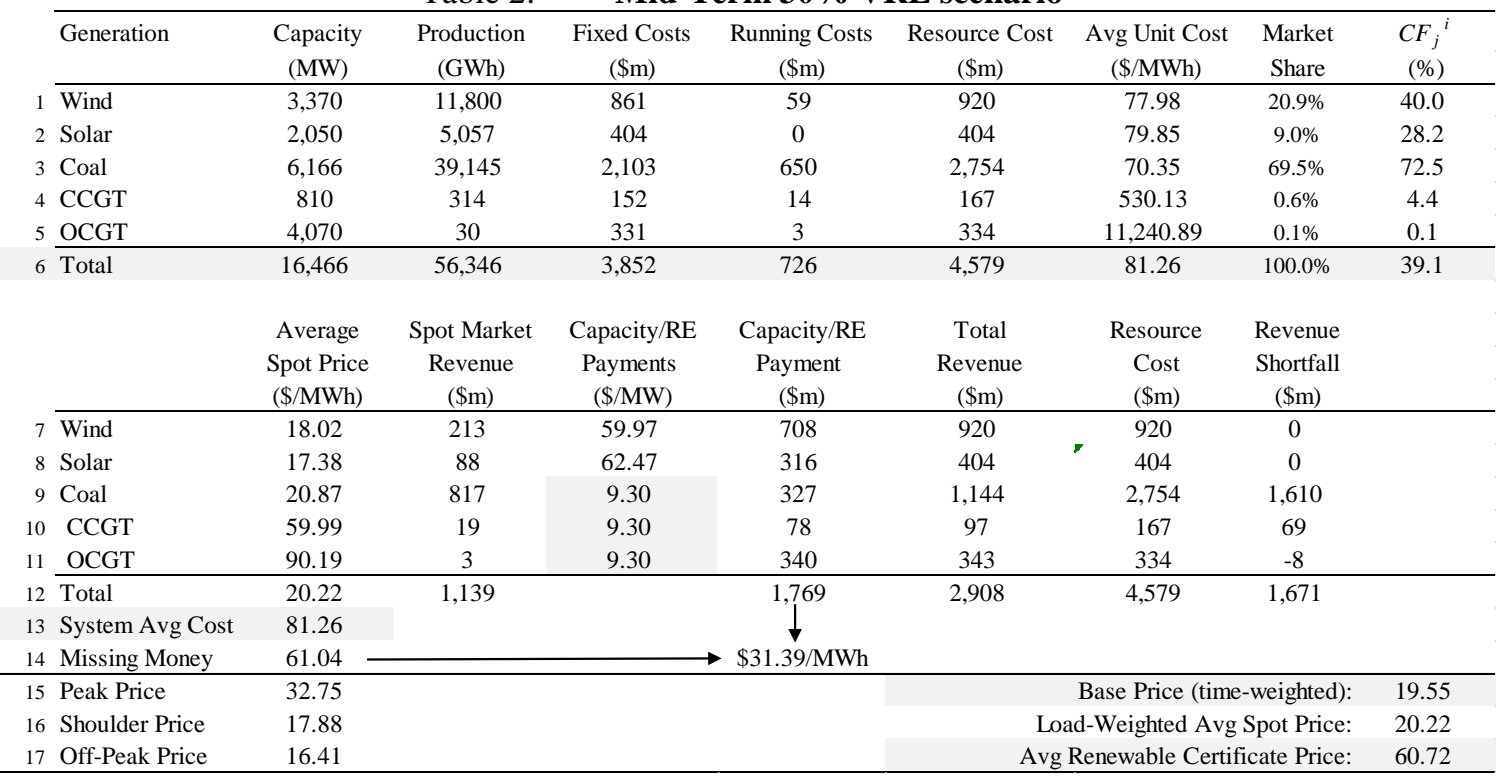

Falling Base Prices are unsustainable. In the Long-Term thermal plant are forced to exit and adjust. Table 3 shows perfect adjustment; compared to the Base Case - at 30\% VRE market share 2000MW of Coal exits and 900MW of flexible gas plant enters. Base Price (line 15) is restored to $\$ 46.23 / \mathrm{MWh}$ and capacity payments $(\$ 9.30 / \mathrm{MW})$ clear missing money. Renewable Certificates fall to $\$ 38.30 / \mathrm{MWh}$.

Table 3: Long-term 30\% VRE scenario

\begin{tabular}{|c|c|c|c|c|c|c|c|c|c|}
\hline & Generation & $\begin{array}{c}\text { Capacity } \\
\text { (MW) }\end{array}$ & $\begin{array}{c}\text { Production } \\
(\mathrm{GWh})\end{array}$ & $\begin{array}{c}\text { Fixed Costs } \\
(\$ \mathrm{~m})\end{array}$ & $\begin{array}{c}\text { Running Costs } \\
(\$ \mathrm{~m})\end{array}$ & $\begin{array}{c}\text { Resource Cost } \\
(\$ \mathrm{~m})\end{array}$ & $\begin{array}{c}\text { Avg Unit Cost } \\
\text { (\$/MWh) }\end{array}$ & $\begin{array}{c}\text { Market } \\
\text { Share }\end{array}$ & $\begin{array}{r}C F_{j}{ }^{i} \\
(\%) \\
\end{array}$ \\
\hline 1 & Wind & 3,274 & 11,490 & 839 & 57 & 896 & 77.98 & $21.0 \%$ & 40.1 \\
\hline 2 & Solar & 1,992 & 4,924 & 393 & 0 & 393 & 79.85 & $9.0 \%$ & 28.2 \\
\hline 3 & Coal & 4,016 & 32,887 & 1,370 & 546 & 1,916 & 58.27 & $60.1 \%$ & 93.5 \\
\hline 4 & CCGT & 962 & 3,574 & 181 & 164 & 345 & 96.39 & $6.5 \%$ & 42.4 \\
\hline 5 & OCGT & 4,173 & 1,843 & 340 & 166 & 506 & 274.60 & $3.4 \%$ & 5.0 \\
\hline 6 & Total & 14,417 & 54,719 & 3,122 & 934 & 4,056 & 74.13 & $100.0 \%$ & 43.3 \\
\hline & & $\begin{array}{l}\text { Average } \\
\text { Spot Price } \\
(\$ / \mathrm{MWh})\end{array}$ & $\begin{array}{c}\text { Spot Market } \\
\text { Revenue } \\
(\$ \mathrm{~m})\end{array}$ & $\begin{array}{c}\text { Capacity/RE } \\
\text { Payments } \\
(\$ / \mathrm{MW})\end{array}$ & $\begin{array}{c}\text { Capacity/RE } \\
\text { Payment } \\
(\$ \mathrm{~m})\end{array}$ & $\begin{array}{c}\text { Total } \\
\text { Revenue } \\
(\$ \mathrm{~m})\end{array}$ & $\begin{array}{c}\text { Resource } \\
\text { Cost } \\
(\$ \mathrm{~m})\end{array}$ & $\begin{array}{c}\text { Revenue } \\
\text { Shortfall } \\
(\$ \mathrm{~m})\end{array}$ & \\
\hline 7 & Wind & 39.74 & 457 & 38.24 & 439 & 896 & 896 & 0 & \\
\hline 8 & Solar & 41.40 & 204 & 38.45 & 189 & 393 & 393 & 0 & \\
\hline 9 & Coal & 48.30 & 1,589 & 9.30 & 327 & 1,916 & 1,916 & 1 & \\
\hline 10 & CCGT & 74.47 & 266 & 9.30 & 78 & 344 & 345 & 0 & \\
\hline 11 & OCGT & 90.19 & 166 & 9.30 & 340 & 506 & 506 & 0 & \\
\hline 12 & Total & 49.01 & 2,681 & & 1,374 & 4,056 & 4,056 & 1 & \\
\hline 13 & System Avg Cost & 74.13 & & & $\downarrow$ & & & & \\
\hline 14 & Missing Money & 25.12 & & & $\$ 25.11 / \mathrm{MWh}$ & & & & \\
\hline 15 & Peak Price & 82.97 & & & & \multicolumn{3}{|c|}{ Base Price (time-weighted): } & 46.23 \\
\hline 16 & Shoulder Price & 47.54 & & & & \multicolumn{3}{|c|}{ Load-Weighted Avg Spot Price: } & 49.01 \\
\hline 17 & Off-Peak Price & 29.97 & & & & \multicolumn{3}{|c|}{ Avg Renewable Certificate Price: } & 38.30 \\
\hline
\end{tabular}

Figure 8 presents the evolution of Base Prices (Mid- and Long-Term) and cost traces for varying levels of VRE market share, along with other elements not obvious or clear from inspection of Tables 1-3. First, the top Line in Figure 8 presents the evolution of System Average Cost, starting at $\$ 64.88$ and rising to $\$ 74.13 / \mathrm{MWh}$ with $30 \%$ VRE. The two Lines immediately below

${ }^{48}$ Note capacity payments are allocated at $\$ 9.30 / \mathrm{MW}$ on the optimal capacity identified in Table 3. 
identify two forces driving System Average Cost movements. (1) The utilisation effect pushes up System Average Cost via a deterioration in the thermal fleet's capacity factor, progressively falling from $61.0 \%$ in the Base Case to $47.8 \%$ in the $30 \%$ VRE scenario. (2) The VRE Cost Differential drives System Average Cost up through the higher cost structure of VRE plant. Of these, utilisation effects are more significant.

Next, note the equilibrium Long-Term Base Price of ca.\$46.26/MWh is maintained throughout any VRE market share provided thermal plant exits and adjusts. The gap between System Average Cost and Long-Term Base Price is the missing money, and is recovered via capacity payments (and Renewable Certificates). The gap between Mid- and Long-Term Base Prices is the merit-order effect, and occurs while thermal plant fails to exit and adjust.

Figure 8: $\quad$ Evolution of system costs \& prices

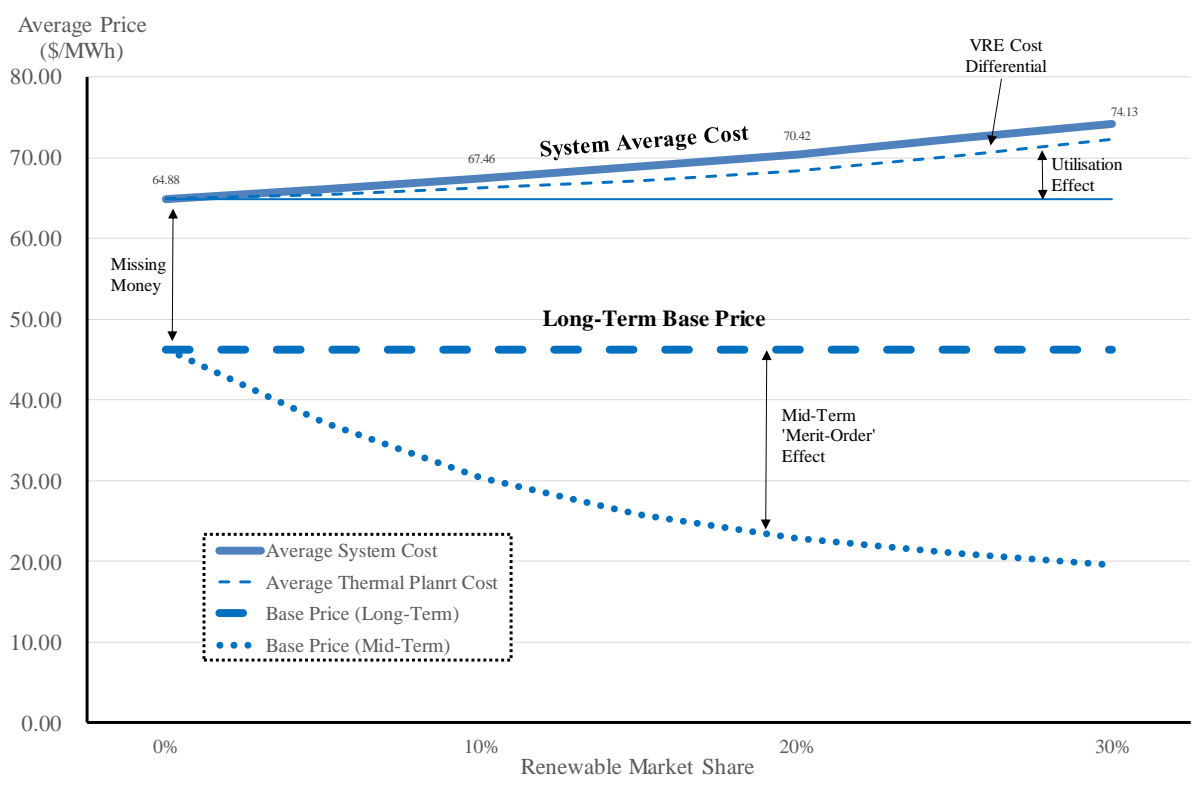

Figures 5-8 and Tables 1-3 identify a series of important results. First, they demonstrate that in theory, energy-only markets can produce a stable equilibrium for any level of VRE up to $30 \%$ (35\% including rooftop solar PV). However, it requires thermal plant to exit and adjust perfectly, and, it requires the optimal level and number of VoLL events in the absence of capacity payments.

Second, two forces work together to force adjustment; (1) merit-order effects damage thermal plant Profit \& Loss Statements through lower prices, and (2) coincident utilisation effects impose further damage by forcing thermal plant up their (downward sloping) cost curves. Consistent with game-changing policy, VRE plant have a side-market which shields them from adverse impacts (i.e. Renewable Certificate subsidies) thus allowing continual entry regardless of how long it takes for thermal plant to exit and adjust.

Finally, market analysis and policy development needs to be thoughtful about merit-order effects. Merit-order effects can be shown to exist, but benefits to consumers translate only in the MidTerm. In the Long-Term, thermal plant will exit and adjust. And to be clear, merit-order effects are not welfare enhancing. ${ }^{49}$

\footnotetext{
${ }^{49}$ Nelson et al. (2012, pp293-295) discuss this in some detail.
} 


\section{On the ability of markets to optimise VRE asset allocation}

Recall from Section 2.5 that static LCoE analyses produce two inherent biases; base over peaking, and stochastic over dispatchable plant (Joskow, 2011). Tables 1 and 3 showed results for 0 and 30\% VRE which revealed certain characteristics about dynamic market values of VRE plant output but a more granular analysis is required, which is presented in Figures 9-13.

\subsection{Static analysis of the value of VRE output at $15 \%$ market share}

Figure 9 shows the evolution of Market Values of Wind output at 15\% market share. Following Hirth (2013), the waterfall chart decomposes the forces progressively affecting wind output market values, in the Mid-Term, and in the Long-Term.

Figure 9: Market Value of wind output (15\% Market Share)

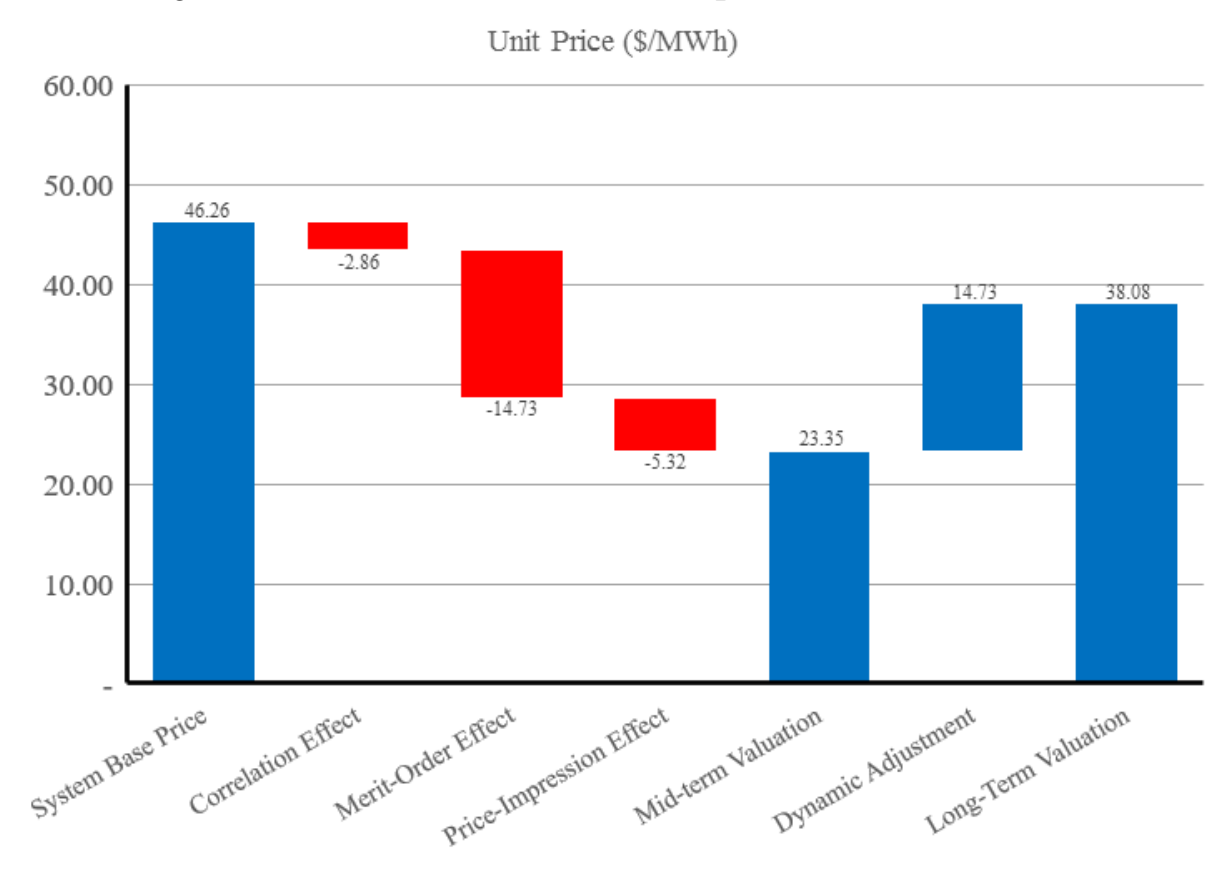

Figure 9 commences with the Base Price $(\$ 46.26 / \mathrm{MWh})$. The first variable impacting the Market Value of Wind output is a correlation effect. QLD wind resources are marginally negatively correlated to wholesale demand and price and so the market value of the first wind farm is marginally below Base Prices (-\$2.86/MWh).

As Wind is progressively added to the plant mix, two further forces impact Market Value; a merit-order effect which is transient, and a price-impression effect, which is enduring. Meritorder effects reflect transient oversupply. Price-impression effects occur because of the stochastic but correlated nature of wind resources. Therefore, as each new wind farm enters, they progressively (and cumulatively) impact Market Values of the entire wind farm fleet (-\$5.32/MWh). In the Mid-Term, the Market Value of Wind output falls to $\$ 23.35 / \mathrm{MWh}$ but merit-order effects are transient and will unwind in the Long-Term, thus rebounding to $\$ 38.08 / \mathrm{MWh}$.

Figure 10 presents the equivalent analysis for utility-scale Solar PV at $15 \%$ market share. This is a striking set of results vis-à-vis price-impression effects and is consistent with Hirth $(2013)^{50}$,

${ }^{50}$ Empirical results in Hirth (2013) from Europe indicate that for every $1 \%$ increase in the market share of Wind, its market value drops by $1.62 \%$ for thermal systems but only $0.22 \%$ for hydro systems (although Hirth cautions that the sample size is small). 
Nicolosi (2012) $)^{51}$ and Mills \& Wiser (2012) ${ }^{52}$. The first bar starts with the Base Price $(\$ 46.26 / \mathrm{MWh})$. Unlike wind, correlation effects of the first solar PV farm are positive because solar output is positively correlated to demand and price $(+\$ 5.33 / \mathrm{MWh})$. Merit-order effects for solar PV are comparatively minor compared to wind (-\$3.39). However, unlike wind which stochastically add energy output across the entire day, solar PV output has a concentrated daytime bias. Price-impression effects are, therefore, acute $(-\$ 25.17 / \mathrm{MWh})$. Consequently, there is little difference between Mid- and Long-Term results because price-impression effects dominate. As Hirth et al. (2016) note, what is special about VRE is not the existence, but the size of the change in system costs as renewables move from low to high market shares.

Figure 10: Market Value of solar output (15\% Market Share)

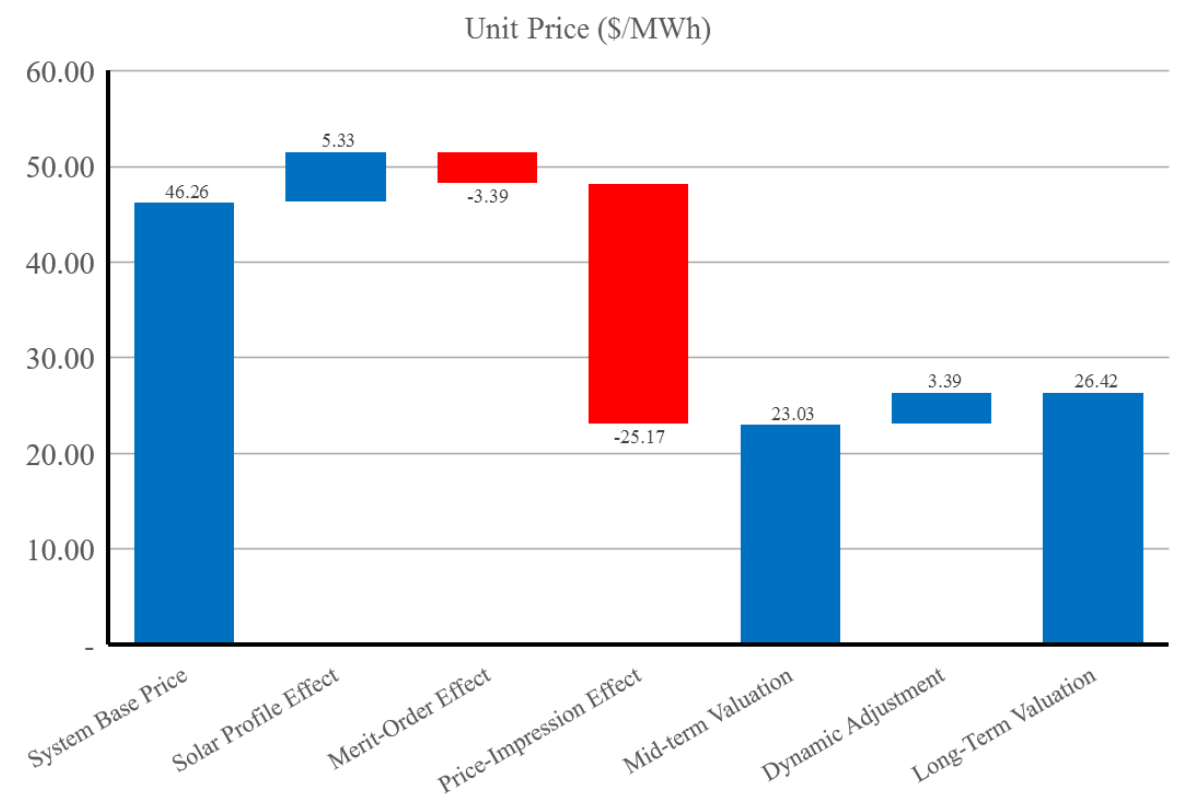

For completeness, dispatchable plant (CCGT) is displayed in Figure 11.

${ }^{51}$ See esp figure 6.17

${ }^{52}$ See especially pp55-57. 
Figure 11: Market value of CCGT output (VRE 15\% market share)

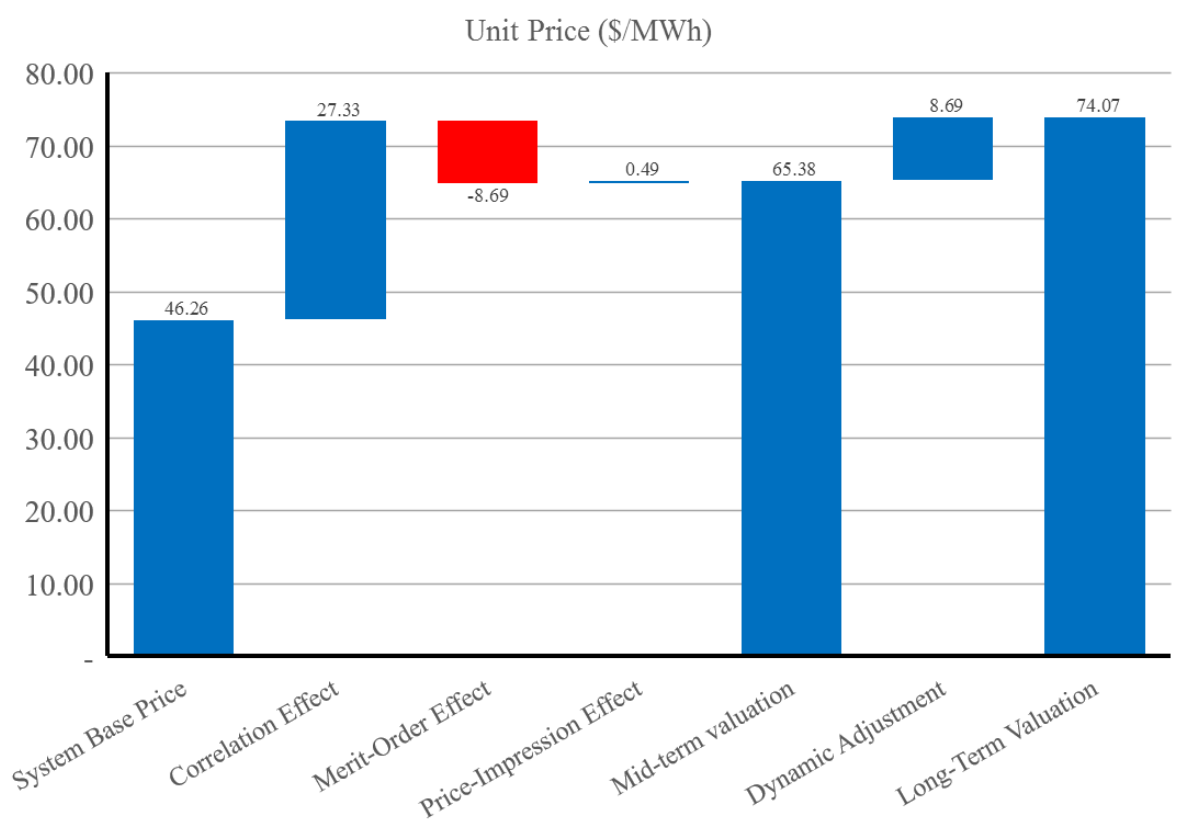

\subsection{Dynamic analysis of the value of VRE output 0-30\% market share}

Figure 12 shows dynamic analyses for wind output market values from 0-30\% market share with continuous adjustment by thermal plant - thus removing transient merit-order effects. Notice the starting point aligns with Figure 9, viz. \$43.80/MWh. Thereafter price-impression effects results in wind output progressively declining to $\$ 35 / \mathrm{MWh}$.

\section{Figure 12: $\quad$ Long-Term Market Value of wind output (0-30\% market share)}

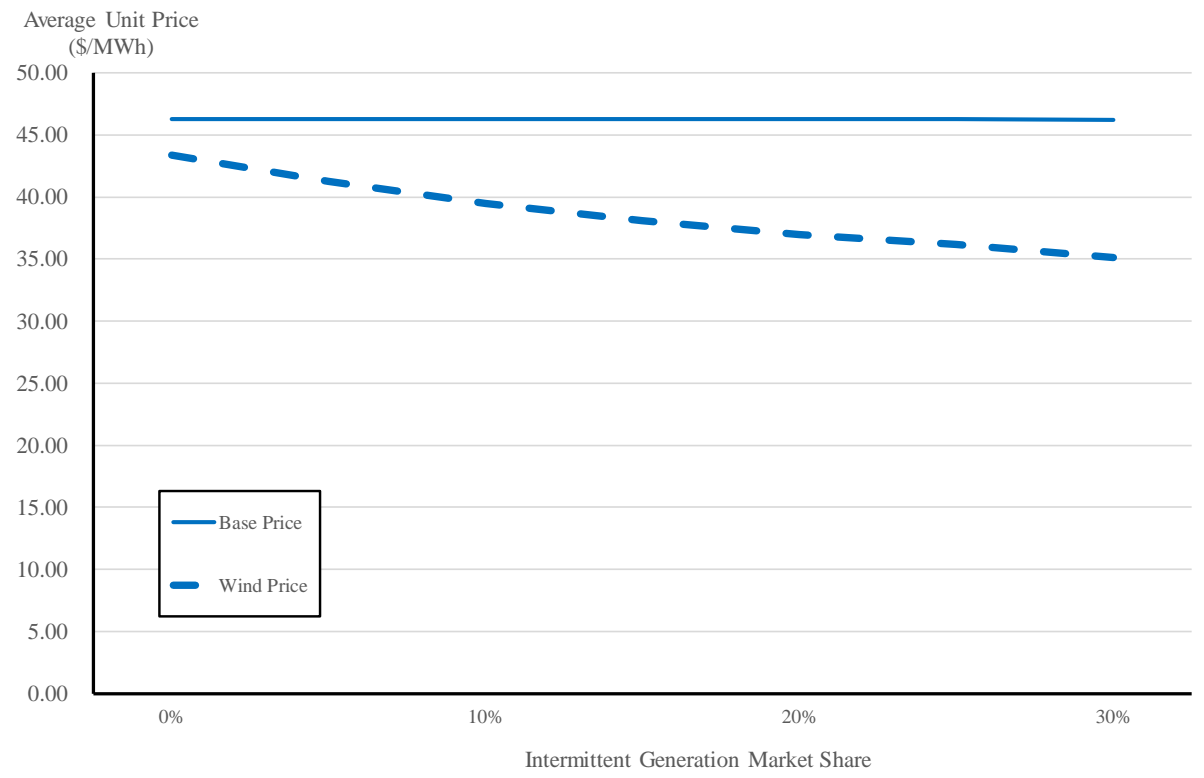

Figure 13 presents the equivalent analysis for solar PV. This result is consistent with Hirth (2013) and others. Because solar PV output is concentrated it has a more acute price-impression effect; essentially, the technology cannibalises itself at a fast rate. 
Figure 13: $\quad$ Long-Term Market Value of solar PV output (0-30\% market share)

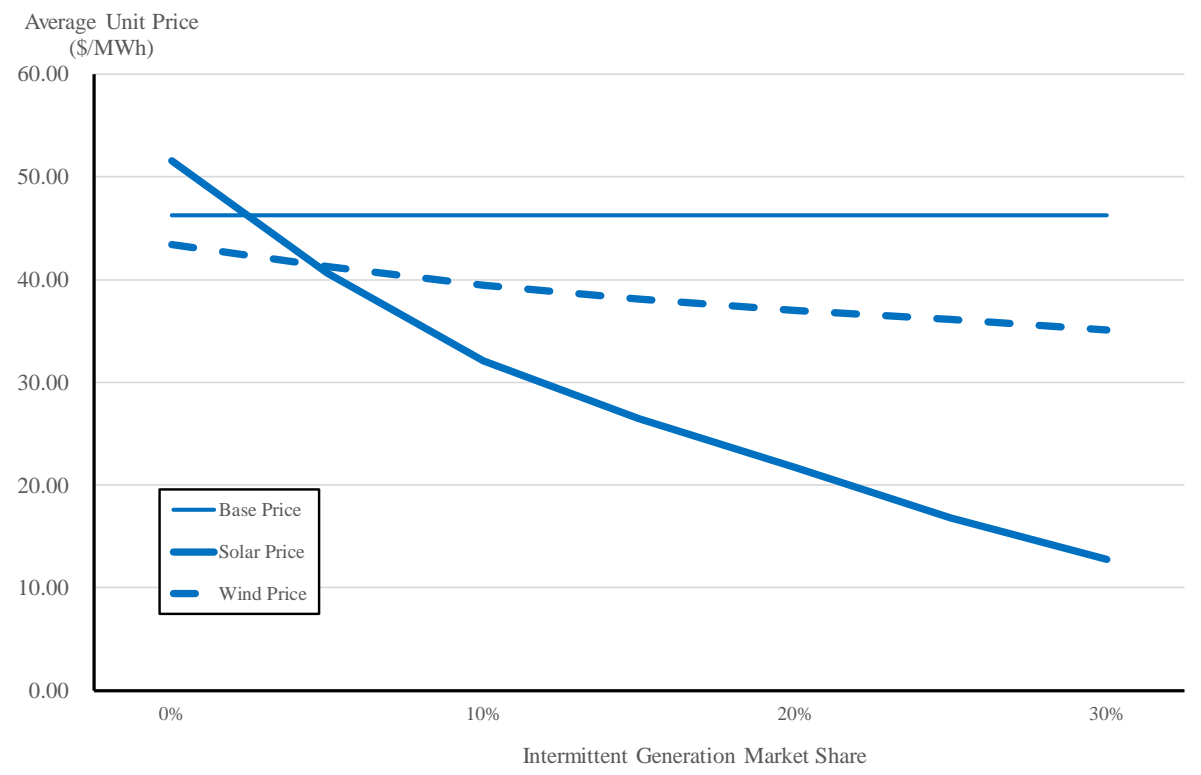

If solar PV is over-represented in the VRE fleet, it is capable of reversing Time-of-Use market prices given costly storage and demand elasticity estimate of -0.10 . Figure 14 presents a dynamic comparison of peak (4pm-8pm), shoulder (7am-4pm, 8pm-10pm) and off-peak (10pm-7am) prices as solar market share increases from 0-30\%. Shoulder (i.e. daytime) prices drop as solar PV market share rises. Conversely, off-peak prices rise as inflexible coal plant exit, off-peak duties increasingly fall on higher-marginal running cost CCGT plant.

Figure 14: Time-of-Use prices \& solar PV 0-30\% market share

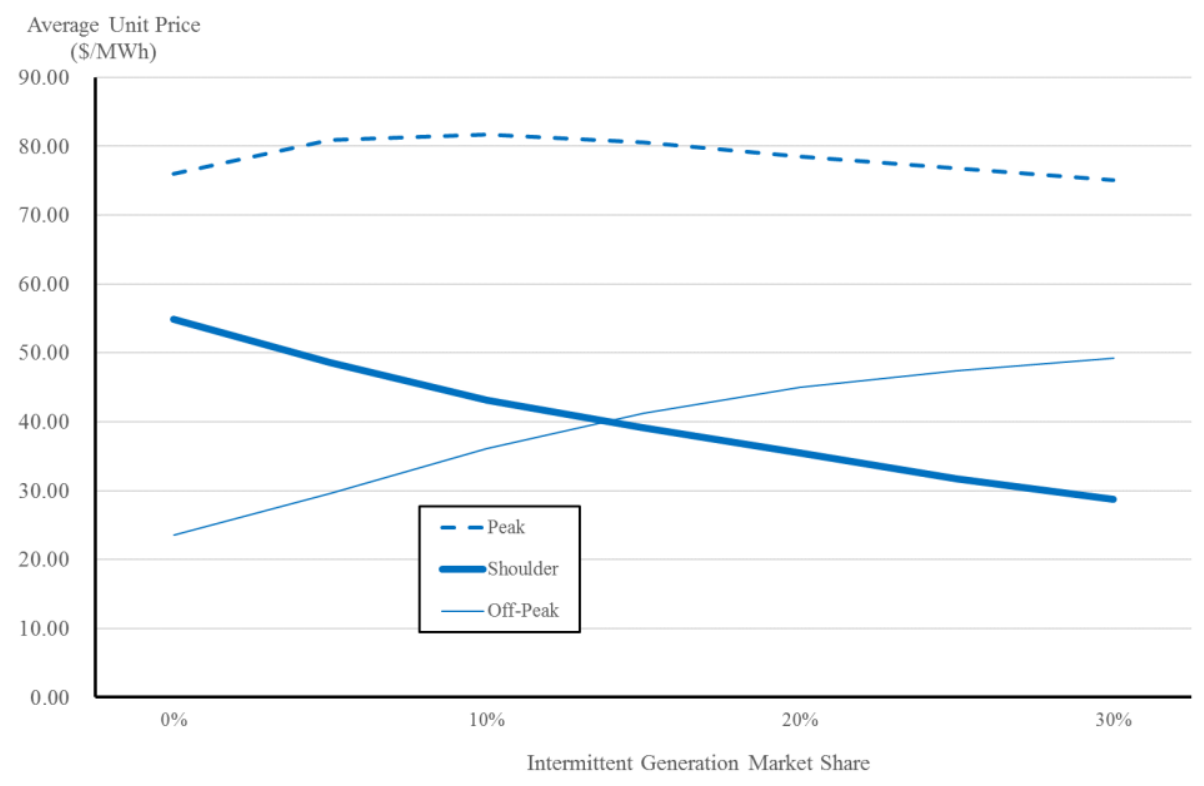

\subsection{On the market's ability to optimise VRE asset allocation}

In theory at least, market participants will optimise the asset allocation of wind and solar PV in the same way that the market regulates and optimises the asset allocation of base and peak plant. When combined with wind resources, there is an optimal solar PV market share higher than that implied in Figure 13 (where solar PV is the only VRE source). Determining optimal VRE asset 
allocation has many dimensions, including total market share of VRE, correlation between wind and solar output, differential rates at which unit costs of technologies decline, site-specific resource endowments \& transmission/connection costs, and speed of thermal plant exit and adjustment. It would be unhelpful to model such rich variation but two variables are worthy of exploration to illustrate the principles; (1) VRE market share, and (2) mix of non-correlated technologies. Figures 15-17 show how the market would regulate asset allocation for VRE Targets of 10\%, 20\% and 30\% market share with thermal plant adjusting perfectly.

It is important to stress that in the following analysis, while system load adjusts for each combination of VRE plant (i.e. own-price elasticity of -0.10), cost estimates for technologies are fixed; viz. all wind and all solar PV plants have identical cost structures to those in Figure 4.

Figure 15 reveals that under these conditions, the optimal asset allocation between wind and solar at 10\% VRE market share is 50/50. As VRE market share rises to 20\%, optimal asset allocation is 60/40 (Figure 16) and finally for 30\% VRE market share, optimal asset allocation is 70/30 (Figure 17). As an aside, Figure 18 presents Time-of-Use prices for the 30\% VRE market share scenario.

Figure 15: Welfare maximising asset allocation: 10\% VRE Target

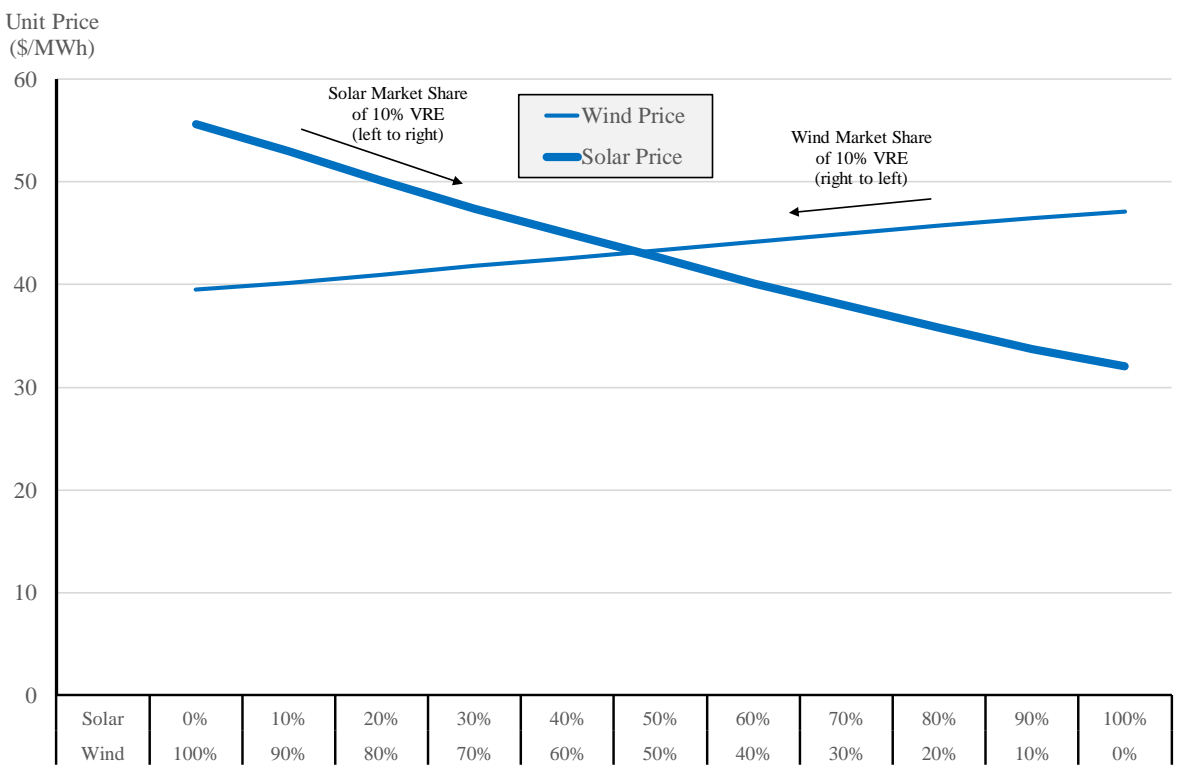


Figure 16: Welfare maximising asset allocation: 20\% VRE Target

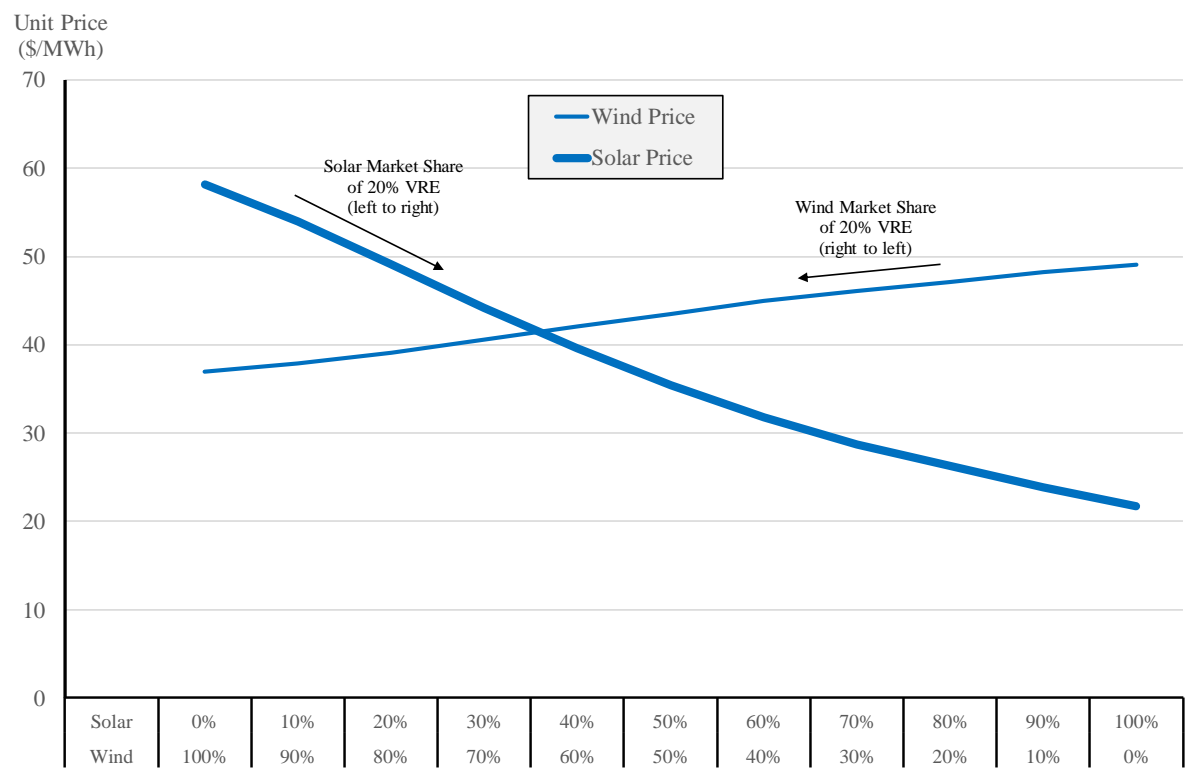

Figure 17: Welfare maximising asset allocation: 30\% VRE Target

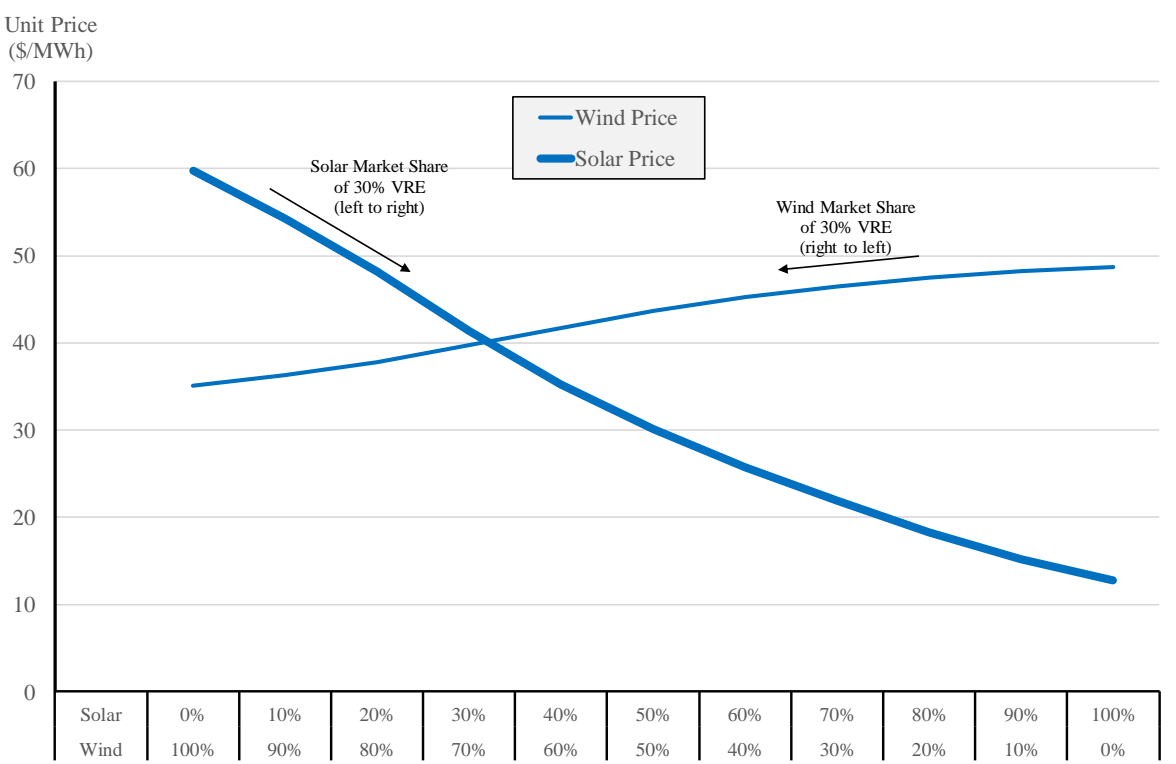


Figure 18: Time-of-Use prices \& optimal VRE asset allocation (0-30\% market share)

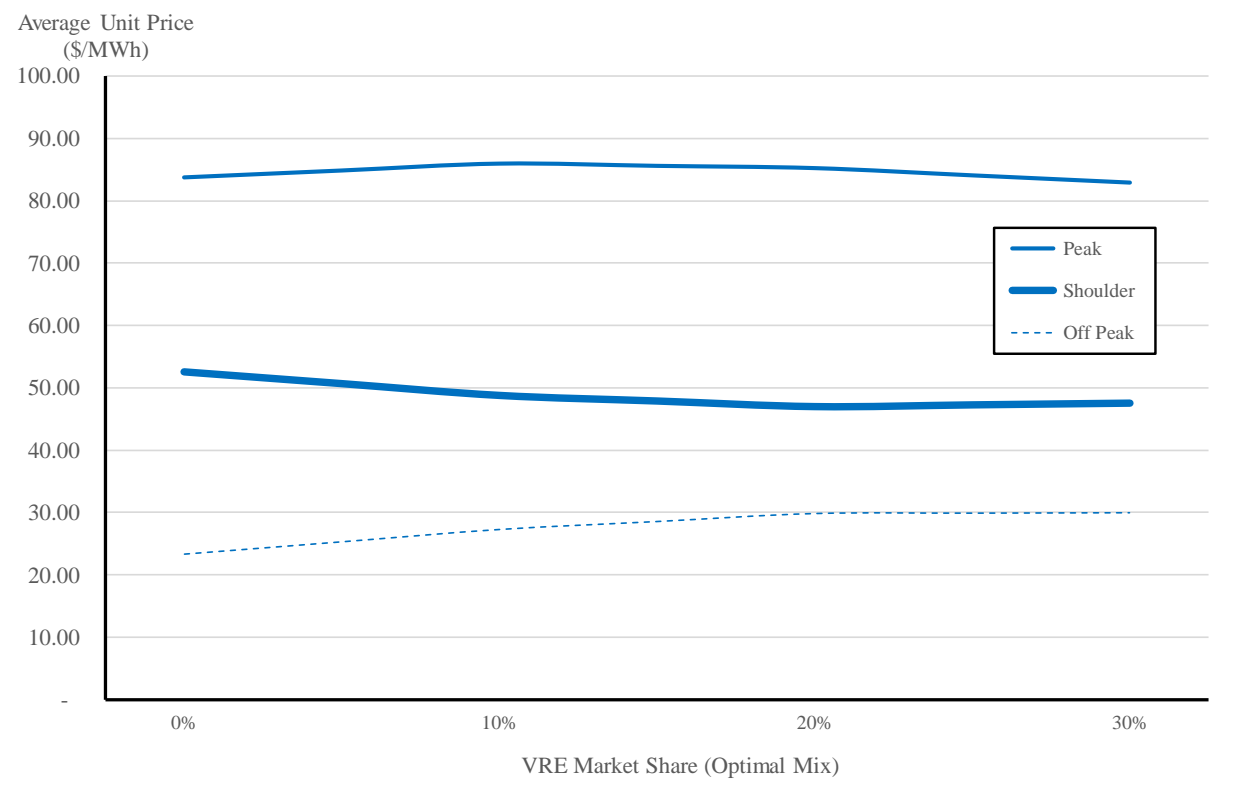

Provided market participants are profit-maximising, focused on the Market Value of output, one should expect the market to regulate entry to an optimal asset allocation. Conversely, government-initiated CfDs based on $\mathrm{LCoE}$ (rather than market value) risk distorting the market, resulting in a misinformed market.

\section{On the stability of the hedge market}

As far as I am aware, there has been no direct analysis of the underlying stability of the market for forward hedge contracts as VRE resources rise and thermal plant exit and adjust in imperfectly interconnected regions. Identifying the supply of hedge contracts is inherently difficult (viz. with turnover of 300-400\%, there are more than just asset-backed traders on the sell-side). But understanding the supply of asset-backed forward contracts provides some indication of stability and systemic security. In Simshauser et al. (2010), individual generation plant capacity was modelled according to a binomial distribution using a Monte Carlo simulation to produce half-hourly availability. The data were then collated and assembled into joint probability availability curves for each generation portfolio, and from there a PoE90 limit was identified as the maximum supply of asset-backed hedges for each portfolio. The same process has been applied in the present analysis assuming 3 large generation portfolios exist, with a more aggressive PoE80 limit for the supply of asset-backed forward contracts (i.e. implying a high degree of co-insurance amongst portfolios).

Figure 19 reveals the results and identifies the possibility of an 'unstable zone' in the hedge market. That is, while Section 3 demonstrated spot markets can reach a tractable equilibrium at $35 \%$ VRE, the hedge market appears to become increasingly unstable as thermal plant exits. To be clear, this is not a Mid-Term problem (i.e. because plant has not exited), it is a Long-Term problem following thermal plant exit.

In Figure 19 the supply of asset-backed hedge contracts (y-axis) is measured against VRE market share (x-axis) with perfect thermal plant exit and adjustment. Maximum System Demand of 9077MW (horizontal line) was a PoE30 weather event, not a PoE10 event which is typically what an energy retailers plan for. Note Total Installed Thermal Plant Capacity starts at 10280MW (per Table 1) and falls to 9141MW (per Table 3). Plant is no longer perfectly available, and so the reserve margin expands from $13 \%$ to $18 \%$ (vis-à-vis Net Load Duration Curve) to meet reliability 
constraints. Total Potential Supply of Hedges (dashed line) represents the average availability of thermal plant given by the average outage rate (viz. starting at $9600 \mathrm{MW}$ and falling to $8500 \mathrm{MW}$ as thermal plant exits). But generators do not hedge $100 \%$ of average expected available capacity - they examine the probability of largest and coincident unit outages in the context of adverse spot prices, and additionally, seek to retain some risk-adjusted spot price exposure. ${ }^{53}$ The PoE80 joint-probability distribution of the thermal generation fleet is represented by the 'Total Practical Supply of Hedges' (solid line) starting at 9200MW and falling to 8200MW.

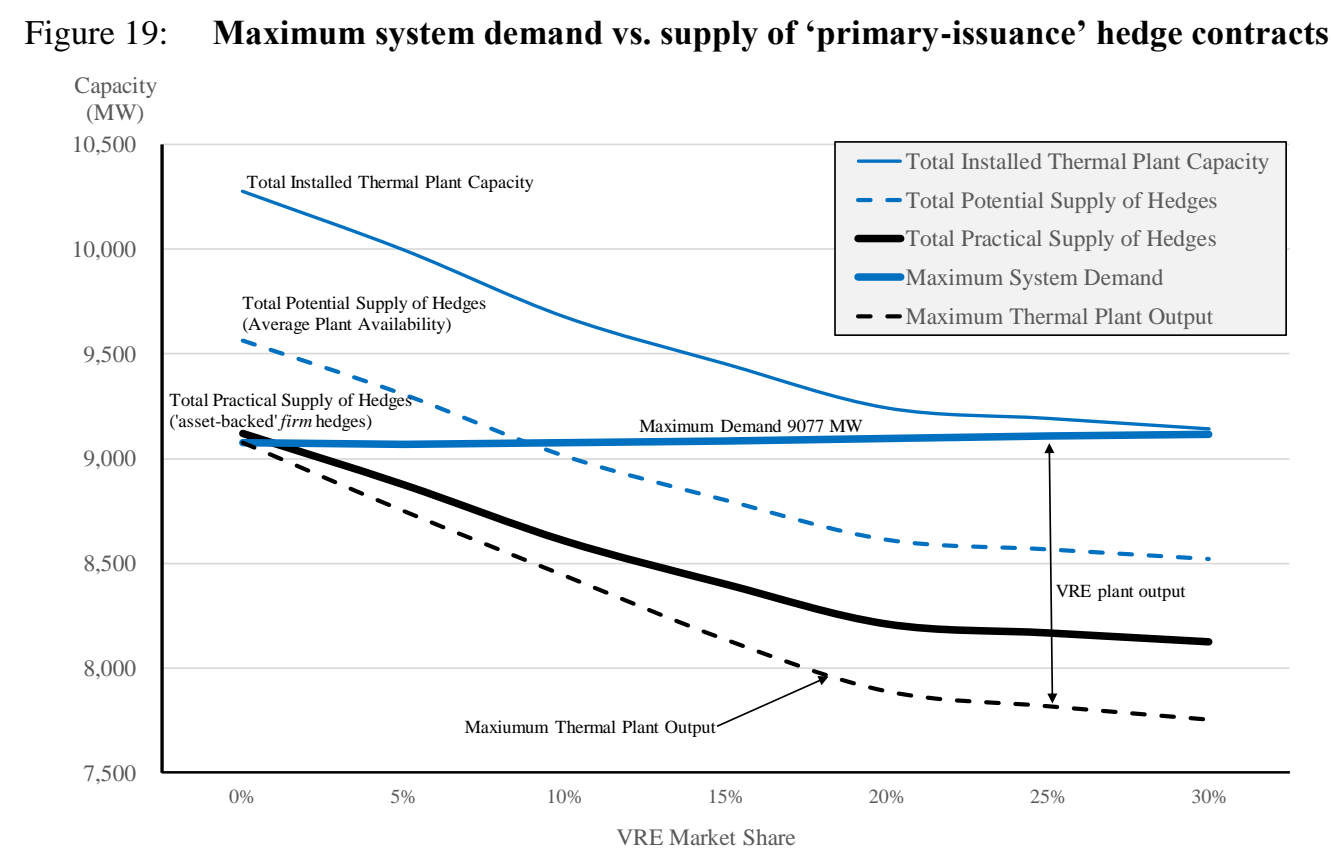

If thermal plant fails to exit or is above optimal levels, no shortage would appear (i.e. Mid-Term). And similarly, even with optimal levels of thermal plant exit and moderate levels of VRE, the market may operate without concern because some component of VRE PPAs will be considered firm, and inter-regional hedges and speculative traders may fill any residual gap. But at high levels of VRE, it is not at all clear that a sufficient supply of asset-backed firm hedge contracts will exist.

If government-initiated CfDs have the compounding effect of extracting non-firm hedge capacity from the market (per Section 2.5), a chronic shortage of hedge contracts may be revealed and weigh heavily on retail competition $-2^{\text {nd }}$ tier non-integrated retailers may be inadvertently foreclosed by this combination of forces. This appears more than a theoretical possibility, with early signs occurring in South Australia at the time of writing.

\section{Concluding remarks}

The purpose of this article was to analyse NEM stability with rising VRE. Starting with a Base Case of coal and gas plant, VRE resources were added until their market share reached 35\% comprising 5\% small-scale and 30\% utility-scale. The literature review revealed energy-only markets are tough neighbourhoods under ideal conditions due to missing money (i.e. extended periods of sub-optimal net revenues), incomplete markets (i.e. absence of buyers for long-dated derivative instruments), missing markets (i.e. no markets for Inertia, Fast Frequency Response, Ramping Duties and forward markets for FCAS), shrinking markets (i.e. the gradual reduction in ${ }^{53}$ The extent to which a generator will seek spot price exposure is a dynamic question. Generator appetite for spot price exposure is
inversely related to the reserve plant margin and any time when base plant is 'under-weight' in the plant mix. 
the supply of asset-backed firm hedge contracts) and misinformed markets (i.e. Governmentinitiated CfDs reliant on LCoE rather than market values).

Section 3 Modelling results confirmed spot electricity markets can maintain equilibrium conditions for the entire envelope of VRE (i.e. 0-35\% market share) provided thermal plant exit and adjust perfectly. If VoLL is correctly priced relative to reliability criteria, and if the market optimises VoLL event frequency, there is no reason to think energy-only markets cannot produce equilibrium conditions. Of course, there is a long way between theory and practice. In the real world, energy-only markets are off equilibrium for extended periods, and rising VRE makes this more, rather than less, likely because of the addition of two new variables requiring optimisation, viz. thermal plant exit, and thermal plant adjustment.

Section 4 analysed optimal VRE asset allocation. Above all, modelling results demonstrated the dangers of LCoE as a metric. LCoE calculations are necessary inputs for power system planning. They are not outputs for investment commitment. As VRE becomes a larger share of the market, sub-national government CfDs execution based on $\mathrm{LCoE}$ analysis may produce a misinformed market through non-rational commitment. Why this matters is prior commitments by market participants, acting in good faith and attempting to acquit policy objectives, can be adversely affected as Figures 9-10 and 12-13 highlight. There is nothing inherently wrong with governments stepping into a market to ensure policy objectives are met, particularly if known market failures exist (e.g. Figures 2-3). But how governments do this is important; they need to play by the same rules otherwise the market may become misinformed.

Section 5 analysed the hedge market with a focus on the supply of asset-backed primary issuance (i.e. firm swaps and caps). As VRE rises hedge contract shortages appear more than a theoretical possibility. There will be no problem in the Mid-Term because excess thermal plant exists as VRE enters. Shortages may become apparent in the Long-Term as thermal plant exits, just as spot prices rebound.

Ironically, in the Mid-Term ample hedge contract capacity will exist because thermal plant will not have exited, but the spot market will be inherently unstable through merit order-effects. Conversely, in the Long-Term the forced exit of thermal plant produces a stable spot market equilibrium but a shortage of asset-backed hedge contract supply. At such a tipping point, only Vertical Retailers will be assured of managing VoLL exposure. $2^{\text {nd }}$ Tier non-integrated retailers may face policy-induced foreclosure. This risk would be heightened if government-initiated CfDs for VRE plant extract non-firm contract supply. Each time a government originates investment, unless there is a purposeful mechanism to 'recycle' underpinning contracts into the hedge market, further shortages may appear. How this is resolved seems worthy of further research.

Ultimately the solution to this Mid-Term/Long-Term disequilibrium may reside in expanding the volumes and services in FCAS markets; this expansion synthetically shifts the demand curve to the right and results in greater system reserves. And as Cramton \& Stoft (2008) note, of all the forms of excess capacity in the energy supply chain, peak generating capacity (viz. OCGT) is least damaging and may well reconcile gaps in the supply of hedge contracts. This also seems worthy of further research.

\section{References}

Agranat, O., MacGill, I. \& Bruce, A. 2015. "Fast frequency markets under high penetrations of renewable energy in the Australian National Electricity Market", 2015 Asia-Pacific Solar Research Conference. 
Anderson, E. J., Hu, X., \& Winchester, D. 2007. Forward contracts in electricity markets: The Australian experience. Energy Policy, 35(5), 3089-3103.

Berrie, T. 1967, "The economics of system planning in bulk electricity supply", Electrical Review, 22(2): 425-428.

Besser, J., Farr, J. \& Tierney, S. 2002, "The political economy of long-term generation adequacy: why an ICAP mechanism is needed as part of standard market design", Electricity Journal, 15(7): 53-62.

Bidwell, M. \& Henney, A. 2004, “Will Neta ensure generation adequacy?”, Power UK, Vol. 122, pp. 1026.

Boiteux, M. 1949, "La tarification des demandes en pointe: Application de la theorie de la vente au cout marginal", Revue Generale de l'Electricite, Translated by H. Izzard in Journal of Business, Boiteux, M. 1960, 'Peak load pricing', Journal of Business, 33(2): 157-80.

Bushnell, J. 2005, "Electricity Resource Adequacy: matching policies and goals", Electricity Journal, 18(8): 11-21.

Bushnell, J., Mansur, E.T. \& Saravia, C., 2007. "Vertical arrangements, market structure, and competition an analysis of restructured US electricity markets". National Bureau of Economic Research.

Cramton P. \& Stoft, S. 2006, "The convergence of market designs for adequate generating capacity with special attention to the CAISOs resource adequacy problem", Cambridge, MA: Center for Energy and Environmental Policy Research.

Campton, P., Ockenfels, A. and Stoft, S. 2013, "Capacity market fundamentals", Economics of Energy \& Environmental Policy, 2(2): 27-46.

Caplan, E. 2012. What drives new generation construction? an analysis of the financial arrangements behind new electric generation projects in 2011. The Electricity Journal, 25(6), 48-61.

Chao, H.-P., Oren, S., \& Wilson, R. 2008. Reevaluation of Vertical Integration and Unbundling in Restructured Electricity Markets. In F. P. Sioshansi (Ed.), Competitive Electricity Markets : Design, Implementation, Performance. Oxford, UK: Elsevier

Chester, L. 2006. The conundrums facing Australia's national electricity market. Economic Papers, 25(4), 362-377.

Dargue, M. \& Koenders, D. 2016, “Are the winds changing on renewables?”, Citi Equities Research Utilities Australia/NZ, Sydney.

de Vries, L. 2003, “The instability of energy-only electricity markets", Research Symposium: European Electricity Markets, The Hague, September 2003.

de Vries, L. 2004, "Securing the public interest in electricity generation markets, the myths of the invisible hand and the copper plate", PhD Dissertation, Delft University of Technology, The Netherlands.

de Vries, L. And Heijnen, P. 2008, “The impact of electricity market design upon investment under uncertainty: the effectiveness of capacity mechanisms", Utilities Policy, 16(2008): 215-227.

Edenhofer, O., Hirth, L., Knopf, B., Pahle, M., Schlomer, S., Schmid, E. and Ueckerdt, F. 2013, “On the economics of renewable energy sources", Energy Economics, 40(2013): S12-S23.

Finon, D. 2008, "Investment risk allocation in decentralised markets: the need of long-term contracts and vertical integration", OPEC Energy Review, 32(2): 150-183. 
Finon, D. \& Pignon, V. 2008, "Electricity and long-term capacity adequacy: the quest for regulatory mechanisms compatible with electricity markets", Utilities Policy, 16(2008): 143-158.

Green, R. 1999, "Draining the pool: the reform of electricity trading in England \& Wales", Energy Policy, 27(9): 515-525.

Green, R. 2006. Market power mitigation in the UK power market. Utilities Policy, 14(2), 76-89.

Green, R. \& Staffell, 2016, “Electricity in Europe: exiting fossil fuels?”, Oxford Review of Economic Policy, 32(2): 282-303.

Helm, D. 2014, "The return of the CEGB? Britain's central buyer model”, Energy Futures Network Paper No.4, available at http://www.dieterhelm.co.uk/assets/secure/documents/The-return-of-the-CEGB.pdf (Accessed January 2017).

Hirth, L. 2013. "The market value of variable renewables: the effect of solar \& wind power variability on their relative price", Energy Economics, 38(2013): 218-236.

Hirth, L. Ueckerdt, F. and Edenhofer, O. 2016, "Why wind is not coal: on the economics of electricity generation", The Energy Journal, 37(3): 1-27.

Hansen, C. 2004. Improving hedge market arrangements in New Zealand. Paper presented at the the sixth Annual National Power New Zealand Conference, Auckland, New Zealand.

Hogan, W., 2005. 'On an 'Energy-Only' Electricity Market Design for Resource Adequacy”. Centre for Business and Government, John F Kennedy School of Government, Harvard University, Cambridge.

Hogan, W. 2013. "Electricity scarcity pricing through operating reserves", Economics of Energy \& Environmental Policy, 2(2): 65-86.

Hogan, S., \& Meade, R. 2007. Vertical integration and market power in electricity markets. New Zealand Institute for the Study of Competition and Regulation working paper, February.

Howell, B., Meade, R., \& O'Connor, S. 2010. Structural separation versus vertical integration: Lessons for telecommunications from electricity reforms. Telecommunications Policy, 34(7), 392-403.

Joskow, P. 2006, "Competitive electricity markets and investment in new generating capacity", AEIBrookings Joint Centre for Regulatory Studies, Working Paper No.06-14.

Joskow, P. 2008, "Capacity payments in imperfect electricity markets: need and design", Utilities Policy, 16(2008): 159-170.

Joskow, P. 2011, "Comparing the costs of intermittent and dispatchable electricity generating technologies”, American Economic Review, 100(3): 238-241.

Joskow, P. 2013, "Symposium on Capacity Markets", Economics of Energy \& Environmental Policy, 2(2): v-vi.

Keay, M. 2016, "Electricity markets are broken - can they be fixed?", OIES Paper EL17, The Oxford Institute for Energy Studies, University of Oxford.

Keeratimahat, K., Bruce, A. \& MacGill, I. 2016. "Review of very short term frequency management strategies for integration of high penetrations of non-synchronous utility-scale PV in electricity markets", Asia-Pacific Solar Research Conference.

Leautier, T-O. 2016, "The visible hand: ensuring optimal investment in electric power generation", The Energy Journal, 37(2): 89-109. 
MacGill, I. 2010. "Electricity market design for facilitating the integration of wind energy: experience and prospects with the Australian National Electricity Market”, Energy Policy, 38(2010): 3180-3191.

Mansur, Erin T., 2007. Upstream competition and vertical integration in electricity markets. J. Law Econ. 50 (1), 125-156.

Meade, R., \& O'Connor, S. 2009. Comparison of long-term contracts and vertical integration in decentralised electricity markets. http://econpapers.repec.org/paper/rscrsceui/2009_2f16.htm

Meyer, R. 2012. Vertical economies and the costs of separating electricity supply - a review of theoretical and empirical literature. The Energy Journal, 33(4), 161-185.

Mills, A. \& Wiser, R. 2012. "Changes in the economic value of variable generation at high penetration levels: a pilot case study of California”, LBNL-5445E, Lawrence Berkeley National Laboratory.

Nelson, J. and Simshauser, P. 2013, "Is the Merchant Power Producer a Broken Model?", Energy Policy, 53(2013): 298-310.

Nelson, T., Nelson, J., Ariyaratnam, J \& Camroux, S. 2013, “An analysis of Australia's large scale renewable energy target: Restoring market confidence", Energy Policy, 62(2013): 386-400.

Nelson, T., Simshauser, P., and Nelson, J. 2012, 'Queensland solar feed-in tariffs and the merit-order effect: economic benefit, or regressive taxation and wealth transfers?', Economic Analysis and Policy, 42(3): 277-301.

Nelson, T. and Orton, F. 2016, “Australia's National Electricity Market: optimising policy to facilitate demand-side response", 49(2): 146-168.

Neuhoff, K. and De Vries, L. 2004, "Insufficient incentives for investment in electricity generation", $C M I$ Working Paper 42, Cambridge.

Neuhoff, K., Wolter, S. and Schwenen, S. 2016, "Power markets with renewables: new perspectives for the European Target Model", The Energy Journal, 37(S12): 23-38.

Newbery, D. 2006, "Market Design”, EPRG Working Paper No. 0515, University of Cambridge. Available at http://www.eprg.group.cam.ac.uk/category/publications/working-paper-series

Nicolosi, M. 2012. The economics of renewable electricity market integration. An empirical and modelbased analysis of regulatory frameworks and their impacts on the power market, Ph.D. thesis, University of Cologne.

Oren, S. 2003, "Ensuring generation adequacy in competitive electricity markets", University of California Energy Institute - Energy Policy \& Economics 007, University of California, Berkley.

Peluchon, B. 2003, "Is investment in peak generation assets efficient in a deregulated electricity sector?", Research Symposium: European Electricity Markets, The Hague, September 2003.

Pollitt, M. 2004, "Electricity reform in Chile: lessons for developing countries", Working Paper 04-016, CEEPR, University of Cambridge. Available at https://dspace.mit.edu/handle/1721.1/45024 (Accessed January 2016)

Pollitt, M. and Anaya, K. 2016, "Can current electricity markets cope with high shares of renewables? A comparison of approaches in Germany, the UK and the State of New York", The Energy Journal, 37(S12): 69-88.

Riesz, J., Gilmore, J. \& MacGill, I. 2015, "Frequency control ancillary service market design: insights from the Australian National Electricity Market", The Electricity Journal, 28(3): 86-99. 
Rivard B. and Yatchew, A. 2016, "Integration of renewables into the Ontario electricity system", The Energy Journal, 37(S12): 221-242.

Roques, F., Newbery, D. \& Nuttall, W. 2005, "Investment incentives and electricity market design: the British experience", Review of Network Economics, 4(2): 93-127.

Sensfu $\beta$, F., Ragwitz, M. \& Genoese, M. 2008, "The merit-order effect: A detailed analysis of the price effect of renewable electricity generation on spot market prices in Germany", Energy Policy, 36(2008): 3086-3094.

Schweppe, F., Caramanis, M., Tabors, R. \& Bohn, R. (1988), Spot pricing of electricity, Kluwer Academic Publishers, London.

Simshauser, P. 2005. The gains from the microeconomic reform of the power generation industry in eastcoast Australia Economic Analysis \& Policy, 35(1/2), 23-43.

Simshauser, P. 2008, "The dynamic efficiency gains from introducing capacity payments in the National Electricity Market", Australian Economic Review, 41(4):349-370.

Simshauser, P. 2010. Vertical integration, credit ratings and retail price settings in energy-only markets: Navigating the Resource Adequacy problem. Energy Policy, 38(11), 7427-7441.

Simshauser, P. 2011. The hidden cost of wind generation in a thermal power system: what cost?, Australian Economic Review, 44(3): 269-292.

Simshauser, P. Molyneux, E. \& Shepherd, M. 2010. "The Entry Cost Shock and the Re-rating of Power Prices in New South Wales, Australia", Australian Economic Review, 43(2): 114-135.

Simshauser P. \& Nelson, T. 2015. "Australia's coal seam gas boom and the LNG entry result", Australian Journal of Agricultural and Resource Economics, 59(2015): 602-623.

Spees, K., Newell, S. and Pfeifenberger, J. 2013, "Capacity markets - lessons learned from the first decade”, Economics of Energy \& Environmental Policy, 2(2): 1-26.

Wen, F., Wu, F. and Ni, Y. 2004, "Generation capacity adequacy in the competitive electricity market environment", Electrical Power \& Energy Systems, Vol.26, pp. 365-372. 


\section{APPENDIX - NEMESYS-PF Model \& Data Inputs}

In order to analyse the stability of Australia's NEM, two models have been formally integrated, (1) the PF Model (Simshauser \& Ariyaratnam, 2014), and NEMESYS (Simshauser, 2011). The two-stage model produces generalised long run marginal cost estimates for generating plant via a dynamic, multi-period post-tax discounted cash flow model. It solves for multiple generating technologies, business combinations and revenue possibilities, and simultaneously solves for convergent price, debt-sizing, taxation and equity returns $K_{e}$. The first-stage outputs are similar to levelised cost estimates but with a level of detail beyond the typical LCOE Model because corporate or project financing and taxation variables and constraints are co-optimised. The second-stage of the model is a stochastic, security-constrained partial equilibrium unit commitment model with half-hourly resolution and price formation based on a uniform, first price auction mechanism. As with Bushnell (2010), it assumes perfect competition, transmission and ramp-rates, free entry and exit to install any combination of divisible capacity that satisfies differentiable equilibrium conditions, with VRE output being exogeneously determined (i.e. by way of policy). Key data inputs are as follows:

Table A1 - Technology Assumptions

\begin{tabular}{|c|c|c|c|c|c|c|c|}
\hline Reference Plant & Unit & $i=$ & Black Coal & CCGT & OCGT & Wind & Solar \\
\hline Plant Capacity & MW & $k$ & 900 & 400 & 225 & 200 & 100 \\
\hline Capacity Factor & $\%$ & $C F$ & 90.0 & 59.9 & 27.4 & 39.7 & 29.3 \\
\hline Auxillary Load & $\%$ & Aux & 6.0 & 3.0 & 1.0 & 1.0 & 1.0 \\
\hline Thermal Efficiency & $\%$ & $\zeta$ & 39.0 & 55.0 & 36.0 & $\mathrm{n} / \mathrm{a}$ & $\mathrm{n} / \mathrm{a}$ \\
\hline Raw Fuel & \$/GJ & $F$ & 1.80 & 7.00 & 8.00 & $\mathrm{n} / \mathrm{a}$ & $\mathrm{n} / \mathrm{a}$ \\
\hline Variable O\&M & \$/MWh & $v$ & 1.28 & 4.08 & 10.19 & 12.23 & 5.50 \\
\hline Fixed O\&M & \$/MW & $f$ & 52,768 & 10,188 & 4,075 & 40,750 & 20,000 \\
\hline Combustion Emissions & $\mathrm{kg} \mathrm{CO} 2 / \mathrm{GJ}$ & $\dot{\mathrm{g}}$ & 90.2 & 50.6 & 50.1 & - & - \\
\hline Fugituive Emissions & $\mathrm{kg} \mathrm{CO} 2 / \mathrm{GJ}$ & $\hat{\mathrm{g}}$ & 8.7 & 18.6 & 5.5 & - & - \\
\hline Overnight Capital Cost & $\$ / \mathrm{kW}$ & $X$ & 2,500 & 1,200 & 732 & 2,000 & 2,000 \\
\hline Capital Works & $\$ \mathbf{\prime}^{\prime} 000$ & $x$ & 5,000 & 2,000 & 1,000 & 1,000 & 1,000 \\
\hline Useful Life & Yrs & $L$ & 40 & 30 & 30 & 25 & 25 \\
\hline
\end{tabular}

Table A2 - Corporate Financing Assumptions

\begin{tabular}{|l|c|c|r|}
\hline Model Variable & Unit & & \\
\hline Inflation & $\%$ & $C P I$ & 2.5 \\
\hline Equity Returns (VI) & $\%$ & $\beta_{\mathrm{VI}}$ & 11.0 \\
\hline Equity Returns (IPP) & $\%$ & $\beta_{\mathrm{IPP}}$ & 15.0 \\
\hline Tax Rate & $\%$ & $\tau_{c}$ & 30.0 \\
\hline Effective Tax Rate & $\%$ & $\tau_{e}$ & 21.3 \\
\hline 3 Yr Interest Rate Swap & $\%$ & $\mathrm{R}_{\mathrm{T}}$ & 2.20 \\
\hline 7 Yr Interest Rate Swap & $\%$ & $\mathrm{R}_{\mathrm{T}}$ & 2.71 \\
\hline PF Credit Spread (3 Yr) & $\mathrm{bps}$ & $\mathrm{C}_{\mathrm{T}}$ & 237 \\
\hline PF Credit Spread (7 Yr) & $\mathrm{bps}$ & $\mathrm{C}_{\mathrm{T}}$ & 229 \\
\hline BBB Credit Spread (3 Yr) & $\mathrm{bps}$ & $\mathrm{C}_{\mathrm{T}}$ & 181 \\
\hline BBB Credit Spread (7 Yr) & bps & $\mathrm{C}_{\mathrm{T}}$ & 194 \\
\hline BBB Credit (FFO/I) & times & $\delta_{\mathrm{VI}}$ & 5.0 \\
\hline BBB Credit (FFO/D) & times & $\omega_{\mathrm{VI}}$ & 0.2 \\
\hline PF DSCR & times & $\delta_{\mathrm{IPP}}$ & 1.35 \\
\hline
\end{tabular}




\subsection{Generalised long run marginal cost estimates}

Costs increase annually by a forecast general inflation rate (CPI). Prices escalate at a discount to CPI. Inflation rates for revenue streams $\pi_{j}^{R}$ and cost streams $\pi_{j}^{C}$ in period (year) $j$ are calculated as follows:

$\pi_{j}^{R}=\left[1+\left(\frac{C P I \times \alpha_{R}}{100}\right)\right]^{j}$, and $\pi_{j}^{C}=\left[1+\left(\frac{C P I \times \alpha_{C}}{100}\right)\right]^{j}$

The discounted value for $\alpha_{R}$ reflects single factor learning rates that characterise generating technologies.

Energy output $\rho_{j}^{i}$ from each plant $(i)$ in each period $(j)$ is a key variable in driving revenue streams, unit fuel costs and variable Operations \& Maintenance costs. Energy output is calculated by reference to installed capacity $k^{i}$, capacity utilisation rate $C F_{j}^{i}$ for each period $j$. Plant auxillary losses $A u x^{i}$ arising from on-site electrical loads are deducted.

$\rho_{j}^{i}=C F_{j}^{i} \cdot k^{i} \cdot\left(1-A u x^{i}\right)$

A convergent electricity price for the $i^{\text {th }}$ plant $\left(p^{i \varepsilon}\right)$ is calculated in year one and escalated per eq. (1). ${ }^{54}$ Thus revenue for the $i^{\text {th }}$ plant in each period $j$ is defined as follows:

$R_{j}^{i}=\left(\rho_{j}^{i} \cdot p^{i \varepsilon} \cdot \pi_{j}^{R}\right)$

Plant marginal running costs are a key variable and used extensively in NEMESYS. In order to define marginal running costs, the thermal efficiency for each generation technology $\zeta^{i}$ needs to be defined. The constant term ' 3600 ' 55 is divided by $\zeta^{i}$ to convert the efficiency result from $\%$ to $\mathrm{kJ} / \mathrm{kWh}$. This is then multiplied by raw fuel commodity cost $f^{i}$. Variable Operations \& Maintenance $\operatorname{costs} v^{i}$, where relevant, are added which produces a pre-carbon short run marginal cost. Under conditions of externality pricing $C P_{j}$, the $\mathrm{CO}_{2}$ intensity of output needs to be defined. Plant carbon intensity $g^{i}$ is derived by multiplying the plant heat rate by combustion emissions $\dot{g}^{i}$ and fugitive $\mathrm{CO}_{2}$ emissions $\hat{g}^{i}$. Marginal running costs in the $j^{\text {th }}$ period is then calculated by the product of short run marginal production costs by generation output $\rho_{j}^{i}$ and escalated at the rate of $\pi_{j}^{C}$.

$\vartheta_{j}^{i}=\left\{\left[\left(\frac{\left(3600 / \zeta^{i}\right)}{1000} \cdot f^{i}+v^{i}\right)+\left(g^{i} \cdot C P_{j}\right)\right] \cdot \rho_{j}^{i} \cdot \pi_{j}^{C} \mid g^{i}=\left(\dot{g}^{i}+\hat{g}^{i}\right) \cdot \frac{\left(3600 / \zeta^{i}\right)}{1000}\right\}$

Fixed Operations \& Maintenance costs $F O M_{j}^{i}$ of the plant are measured in \$/MW/year of installed capacity $F C^{i}$ and are multiplied by plant capacity $k^{i}$ and escalated.

$F O M_{j}^{i}=F C^{i} \cdot k^{i} \cdot \pi_{j}^{C}$

Earnings Before Interest Tax Depreciation and Amortisation (EBITDA) in the $j^{\text {th }}$ period can therefore be defined as follows:

\footnotetext{
${ }^{54}$ Note that thermal plant also earns ancillary services revenue, which in the model equates to about $0.3 \%$ of electricity sales. This has been the historic average although as VRE increases, this can be expected to change dramatically.

55 The derivation of the constant term 3600 is: 1 Watt $=1$ Joule per second and hence 1 Watt Hour $=3600$ Joules.
} 
$\operatorname{EBITDA} A_{j}^{i}=\left(R_{j}^{i}-\vartheta_{j}^{i}-F O M_{j}^{i}\right)$

Capital Costs $\left(X_{0}^{i}\right)$ for each plant $i$ are Overnight Capital Costs and incurred in year $0 .{ }^{56}$ Ongoing capital spending for each period $j$ is determined as the inflated annual assumed capital works program.

$x_{j}^{i}=c_{j}^{i} \cdot \pi_{j}^{C}$

Plant capital costs $X_{0}^{i}$ give rise to tax depreciation $\left(d_{j}^{i}\right)$ such that if the current period was greater than the plant life under taxation law $(L)$, then the value is 0 . In addition, $x_{j}^{i}$ also gives rise to tax depreciation such that:

$d_{j}^{i}=\left(\frac{x_{0}^{i}}{L}\right)+\left(\frac{x_{j}^{i}}{L+1-j}\right)$

From here, taxation payable $\left(\tau_{j}^{i}\right)$ at the corporate taxation rate $\left(\tau_{c}\right)$ is applied to EBITD $A_{j}^{i}$ less Interest on Loans $\left(I_{j}^{i}\right)$ later defined in (16), less $d_{j}^{i}$. To the extent $\left(\tau_{j}^{i}\right)$ results in non-positive outcome, tax losses $\left(L_{j}^{i}\right)$ are carried forward and offset against future periods.

$\operatorname{Max}\left(\tau_{j}^{i}, 0\right)=\left(E B I T D A_{j}^{i}-I_{j}^{i}-d_{j}^{i}-L_{j-1}^{i}\right) \cdot \tau_{c}$

The debt financing model computes interest and principal repayments on different debt facilities depending on the type, structure and tenor of tranches. There are two types of debt facilities - (a) corporate facilities (i.e. balance-sheet financings) and (2) project financings. Debt structures include semi-permanent amortising facilities and bullet facilities.

Corporate facilities involve 3- and 7-year money raised with an implied 'BBB' credit rating. With project financings, two facilities are modelled. The first facility is nominally a 3-year bullet requiring interest-only payments after which it is refinanced with consecutive amortising facilities and fully amortised over a 25-year period. The second facility commences with a tenor of 7 years as an amortising facility, again set within a semi-permanent structure with a nominal repayment term of 25 years. The decision tree for the two tranches of debt was the same, so for the Debt Tranche where $T=1$ or 2 , the calculation is as follows:

if $j\left\{\begin{array}{l}>1, D T_{j}^{i}=D T_{j-1}^{i}-P_{j-1}^{i} \\ =1, D T_{1}^{i}=D_{0}^{i} . S\end{array}\right.$

$D_{0}^{i}$ refers to the total amount of debt used in the project. The split $(S)$ of the debt between each facility refers to the manner in which debt is apportioned to each tranche. In the model, $35 \%$ of debt is assigned to Tranche 1 and the remainder to Tranche 2. Principal $P_{j-1}^{i}$ refers to the amount of principal repayment for tranche $T$ in period $j$ and is calculated as an annuity:

$P_{j}^{i}=\left(\frac{D T_{j}^{i}}{\left[\frac{1-\left(1+\left(R_{T}^{Z}+C_{T}^{Z}\right)\right)^{-n}}{R_{T}^{Z}+C_{T}^{Z}}\right]} \mid z\left\{\begin{array}{c}=V I \\ =P F\end{array}\right)\right.$

\footnotetext{
${ }^{56}$ The model is capable of dealing with multi-period construction programs such that $X_{j}^{i}=-\sum_{k=1}^{N} C_{k} \cdot\left(1+K_{e}\right)^{-k}$. However, for the present exercise, all plant capital costs are 'Overnight Capital Costs' (i.e. as if the plant were purchased at the completion of construction) and therefore include an allowance for capitalised interest during construction.
} 
In (15), $R_{T}$ is the relevant interest rate swap (3yrs or $7 \mathrm{yrs}$ ) and $C_{T}$ is the credit spread or margin relevant to the issued Debt Tranche. The relevant interest payment in the $j^{\text {th }}$ period $\left(I_{j}^{i}\right)$ is calculated as the product of the (fixed) interest rate on the loan by the amount of loan outstanding:

$I_{j}^{i}=D T_{j}^{i} \times\left(R_{T}^{Z}+C_{T}^{Z}\right)$

Total Debt outstanding $D_{j}^{i}$, total Interest $I_{j}^{i}$ and total Principle $P_{j}^{i}$ for the $i^{t h}$ plant is calculated as the sum of the above components for the two debt tranches in time $j$. For clarity, Loan Drawings are equal to $D_{0}^{i}$ in year 1 as part of the initial financing and are otherwise 0 .

One of the key calculations is the initial derivation of $D_{0}^{i}$ (eq.10). This is determined by the product of the gearing level and the Overnight Capital Cost $\left(X_{0}^{i}\right)$. Gearing levels are formed by applying a cash flow constraint based on credit metrics applied by project banks and capital markets. The variable $\gamma$ in our PF Model relates specifically to the legal structure of the business and the credible capital structure achievable. The two relevant legal structures are Vertically Integrated (VI) merchant utilities (using 'BBB' rated corporate facilities) and Inpdependent Power Producers using Project Finance (PF).

if $\gamma\left\{\begin{array}{l}=V I, \operatorname{Min}\left(\frac{F F O_{j}^{i}}{I_{j}^{i}}\right) \geq \delta_{j}^{V I \wedge} \operatorname{Min}\left(\frac{F F O_{j}^{i}}{D_{j}^{i}}\right) \geq \omega_{j}^{V I} \forall j \mid F F O_{j}^{i}=\left(E B I T D A_{j}^{i}-x_{j}^{i}\right) \\ =P F, \operatorname{Min}\left(D S C R_{j}^{i}, L L C R_{j}^{i}\right) \geq \delta_{j}^{P F}, \forall j \mid D S C R_{j}=\frac{\left(E B I T D A_{j}^{i}-x_{j}^{i}-\tau_{j}^{i}\right)}{P_{j}^{i}+l_{j}^{i}}, L L C R_{j}=\frac{\sum_{j=1}^{N}\left[\left(E B I T D A_{j}^{i}-x_{j}^{i}-\tau_{j}^{i}\right) \cdot\left(1+K_{d}\right)^{-j}\right]}{D_{j}^{i}}\end{array}\right.$

The variables $\delta_{j}^{V I}$ and $\omega_{j}^{V I}$ are exogenously determined by credit rating agencies. Values for $\delta_{j}^{P F}$ are exogenously determined by project banks and depend on technology (i.e. thermal vs. renewable) and the extent of energy market exposure, that is whether a Power Purchase Agreement exists or not. For clarity, $F F O_{j}^{i}$ is 'Funds From Operations' while $D S C R_{j}^{i}$ and $L L C R_{j}^{i}$ are the Debt Service Cover Ratio and Loan Life Cover Ratios.

At this point, all of the necessary conditions exist to produce estimates of the long run marginal cost of power generation technologies. The relevant equation to solve for the price $\left(p^{i \varepsilon}\right)$ given expected equity returns $\left(K_{e}\right)$ whilst simultaneously meeting the binding constraints of $\delta_{j}^{V I}$ and $\omega_{j}^{V I}$ or $\delta_{j}^{P F}$ given the relevant business combination is as follows:

$-X_{0}^{i}+\sum_{j=1}^{N}\left[E B I T D A_{j}^{i}-I_{j}^{i}-P_{j}^{i}-\tau_{j}^{i}\right] \cdot\left(1+K_{e}\right)^{-(j)}-\sum_{j=1}^{N} x_{j}^{i} \cdot\left(1+K_{e}\right)^{-(j)}-D_{0}^{i}$

The primary objective is to expand every term which contains $p^{i \varepsilon}$. Expansion of the EBITDA and Tax terms is as follows:

$-X_{0}^{i}+\sum_{j=1}^{N}\left[\left(p^{i \varepsilon} \cdot \rho_{j}^{i} \cdot \pi_{j}^{R}\right)-\vartheta_{j}^{i}-F O M_{j}^{i}-I_{j}^{i}-P_{j}^{i}-\left(\left(p^{i \varepsilon} \cdot \rho_{j}^{i} \cdot \pi_{j}^{R}\right)-\vartheta_{j}^{i}-F O M_{j}^{i}-I_{j}^{i}-d_{j}^{i}-L_{j-1}^{i}\right) \cdot \tau_{c}\right] \cdot(1+$ $\left.K_{e}\right)^{-(j)}-\sum_{j=1}^{N} x_{j}^{i} \cdot\left(1+K_{e}\right)^{-(j)}-D_{0}^{i}$

The terms are then rearranged such that only the $p^{i \varepsilon}$ term is on the left hand side of the equation:

Let $I R R \equiv K_{e}$ 


$$
\begin{aligned}
& \sum_{j=1}^{N}\left(1-\tau_{c}\right) \cdot p^{i \varepsilon} \cdot \rho_{j}^{i} \cdot \pi_{j}^{R} \cdot\left(1+K_{e}\right)^{-(j)}=X_{0}^{i}-\sum_{j=1}^{N}\left[-\left(1-\tau_{c}\right) \cdot \vartheta_{j}^{i}-\left(1-\tau_{c}\right) \cdot F O M_{j}^{i}-\left(1-\tau_{c}\right) \cdot\left(I_{j}^{i}\right)-P_{j}^{i}+\right. \\
& \left.\left.\tau_{c} \cdot d_{j}^{i}+\tau_{c} L_{j-1}^{i}\right) \cdot\left(1+K_{e}\right)^{-(j)}\right]+\sum_{j=1}^{N} x_{j}^{i} \cdot\left(1+K_{e}\right)^{-(j)}+D_{0}^{i}
\end{aligned}
$$

The model then solves for $P^{\varepsilon}$ such that:

$$
\begin{aligned}
& p^{i \varepsilon}=\frac{X_{0}^{i}}{\sum_{j=1}^{N}\left(1-\tau_{c}\right) \cdot P^{\varepsilon} \cdot \rho_{j}^{i} \cdot \pi_{j}^{R} \cdot\left(1+K_{e}\right)^{-(j)}}+\frac{\left.\sum_{j=1}^{N}\left(\left(1-\tau_{c}\right) \cdot \vartheta_{j}^{i}+\left(1-\tau_{c}\right) \cdot F O M_{j}^{i}+\left(1-\tau_{c}\right) \cdot\left(I_{j}^{i}\right)+P_{j}^{i}-\tau_{c} \cdot d_{j}^{i}-\tau_{c} L_{j-1}^{i}\right) \cdot\left(1+K_{e}\right)^{-(j)}\right)}{\sum_{j=1}^{N}\left(1-\tau_{c}\right) \cdot p^{i \varepsilon} \cdot \rho_{j}^{i} \cdot \pi_{j}^{R} \cdot\left(1+K_{e}\right)^{-(j)}}+ \\
& \frac{\sum_{j=1}^{N} x_{j}^{i} \cdot\left(1+K_{e}\right)^{-(j)}+D_{0}^{i}}{\sum_{j=1}^{N}\left(1-\tau_{c}\right) \cdot p^{i \varepsilon} \cdot \rho_{j}^{i} \cdot \pi_{j}^{R} \cdot\left(1+K_{e}\right)^{-(j)}}
\end{aligned}
$$

\subsection{OCGT plant}

Certain adjustments to the Model are required to accommodate long run marginal cost estimates for peaking plant. Defining a single electricity price $p^{i \varepsilon}$ for such plant is meaningless in the absence of an expected fixed $\overline{C F_{J}^{l}}$. Peaking plant requires a distinct revenue model to express generalised long run marginal cost estimates as the 'carrying cost' of plant capacity, $\bar{F}_{0}$. This requires small modifications to the Model. The result produced is a single capacity price $P^{k}$ which reflects the equilibrium price of a sold call-option contract. Eq.(2) and (3) require reconfiguring as follows:

$\rho_{j}^{i}=0 \forall j$, and $R_{j}^{k}=\left(k^{i} \cdot P^{k} \cdot \pi_{j}^{R}\right)$

The value of energy output $\rho_{j}^{i}$ is set to zero which means marginal running costs $\vartheta_{j}^{i}$ will also be zero. In practice $\rho_{j}^{i}$ will have a non-zero value and so $p^{i \varepsilon}$ would also be non-zero, and under most conditions will exceed marginal running costs $\vartheta_{j}^{i}$. The value for $R_{j}^{k}$, which equals $\bar{F}_{0}$, is important as it defines the 'missing money' in an energy-only market under conditions of perfect competition, perfect plant divisibility and availability as Section 3 demonstrates.

\subsection{Security-constrained unit commitment}

The integration of the PF Model and NEMESYS centres around the transposition of three key variables, $p^{i \varepsilon}$, and unit Marginal Running Cost $v^{i}$ and total unit Fixed $\&$ Sunk Costs, $\varphi^{i}$ such that:

$\varphi^{i}=p^{i \varepsilon}-v^{i} \mid\left(v^{i}+\varphi^{i}\right) \cdot \rho_{1}^{i} \equiv R_{1}^{i}$

These two parameters (i.e. Marginal Running Cost $v^{i}$ and Fixed and Sunk Costs $\varphi^{i}$ ) are key variables in the half-hourly power system simulation model, and are used extensively to meet the objective function (see eq.24).

NEMESYS-PF dispatches the fleet of perfectly available and perfectly divisible power generating units to satisfy security constraints and differential equilibrium conditions given specified plant options available. In the power system sub-model, let $H$ be the ordered set of all half-hourly periods.

$n \in\{1 \ldots|H|\} \wedge h_{n} \in H$

\section{Demand Function}

Let $E$ be the set of all electricity consumers in the model. 
$k \in\{1 \ldots|E|\} \wedge e_{k} \in E$

Let $\mathrm{C}_{k}(q)$ be the valuation that consumer segments are willing to pay for quantity $q$ MWh of power. The model assumes that demand in each period $n$ is independent of other demand periods. Let $q_{n k}$ be the metered quantity consumed by customer $e_{n}$ in each period $h_{k}$ expressed in MWh.

\section{Supply Function}

Let $\Psi$ be the set of existing installed power plants and available augmentation options for each relevant scenario.

$i \in\{1 \ldots|\Psi|\} \wedge \psi^{i} \in \Psi$

As outlined in eq.19, let $\varphi^{i}$ be the fixed operating \& sunk capacity costs and $v^{i}$ be the marginal running cost of plant $\psi^{i}$ respectively. Let $\overline{\rho^{l}}$ be the maximum continuous rating of power plant $\psi^{i}$. Power plants can be subject to scheduled and forced outages. $\mathrm{F}(n, i)$ is the availability of plant $\psi^{i}$ in each period $h_{n}$. Annual plant availability is therefore:

$\sum_{j=0}^{|P|} F(n, i) \forall \psi^{i}$

Let $O_{n, i}$ be the quantity of power produced by plant $\psi^{i}$ in each period $h_{n}$.

\section{Objective Function}

Optimal welfare will be reached by maximising the sum of producer and consumer surplus, given by the integral of the aggregate demand curve less power production costs. The objective function is therefore expressed as:

$O b j=\sum_{n=1}^{|H|} \sum_{i=k}^{|E|} \int_{q=0}^{e_{k}} C_{k}(q) d q-\sum_{n=1}^{|H|} \sum_{\psi=1}^{|\Psi|}\left(O_{\psi^{i}} \cdot v^{i}\right)-\sum_{\psi=1}^{|\Psi|}\left(O_{\psi^{i}} \cdot \varphi^{i}\right)$

Subject to $\sum_{i=1}^{|E|} q_{k n} \leq \sum_{\psi=1}^{|\Psi|} O_{\psi^{i}}^{\wedge} 0 \leq O_{n i} \leq \mathrm{F}(n, i)^{\wedge} 0 \leq O_{n, i} \leq \overline{\rho^{l}}$ 